\title{
An Improved Calibration Method for Hydrazine Monitors for the United States Air Force
}

Phase 1 of Air Force Hydrazine Detector

Characterization and Calibration Project

\author{
June 6, 2003
}

Prepared by

Kofi Korsah, William P. Murray, and Bruce A. Tomkins 


\title{
DOCUMENT AVAILABILITY
}

Reports produced after January 1, 1996, are generally available free via the U.S. Department of Energy (DOE) Information Bridge.

Web site http://www.osti.gov/bridge

Reports produced before January 1, 1996, may be purchased by members of the public from the following source.

\author{
National Technical Information Service \\ 5285 Port Royal Road \\ Springfield, VA 22161 \\ Telephone 703-605-6000 (1-800-553-6847) \\ TDD 703-487-4639 \\ Fax 703-605-6900 \\ E-mail info@ntis.fedworld.gov \\ Web site http://www.ntis.gov/support/ordernowabout.htm
}

Reports are available to DOE employees, DOE contractors, Energy Technology Data Exchange (ETDE) representatives, and International Nuclear Information System (INIS) representatives from the following source.

Office of Scientific and Technical Information

P.O. Box 62

Oak Ridge, TN 37831

Telephone 865-576-8401

Fax 865-576-5728

E-mail reports@adonis.osti.gov

Web site http://www.osti.gov/contact.html

This report was prepared as an account of work sponsored by an agency of the United States Government. Neither the United States government nor any agency thereof, nor any of their employees, makes any warranty, express or implied, or assumes any legal liability or responsibility for the accuracy, completeness, or usefulness of any information, apparatus, product, or process disclosed, or represents that its use would not infringe privately owned rights. Reference herein to any specific commercial product, process, or service by trade name, trademark, manufacturer, or otherwise, does not necessarily constitute or imply its endorsement, recommendation, or favoring by the United States Government or any agency thereof. The views and opinions of authors expressed herein do not necessarily state or reflect those of the United States Government or any agency thereof. 


\title{
An Improved Calibration Method for Hydrazine Monitors for the United States Air Force
}

Phase 1 of Air Force Hydrazine Detector

Characterization and Calibration Project

Kofi Korsah, William P. Murray, and Bruce A. Tomkins

Date Published: June 2003

\author{
Prepared by \\ OAK RIDGE NATIONAL LABORATORY \\ P.O. Box 2008 \\ Oak Ridge, Tennessee 37831-6285 \\ managed by \\ UT-Battelle, LLC \\ for the \\ U.S. Air Force \\ under MIPR number N0087000000042
}




\section{CONTENTS}

Page

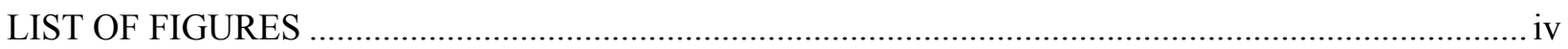

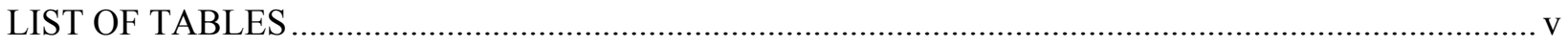

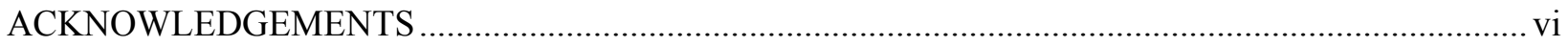

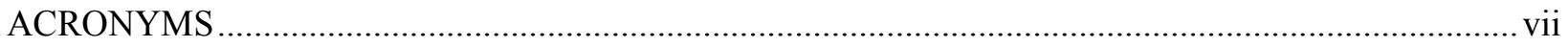

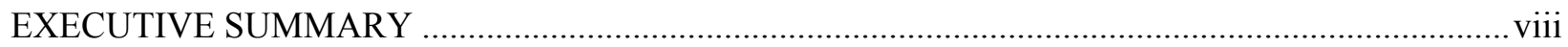

1 INTRODUCTION

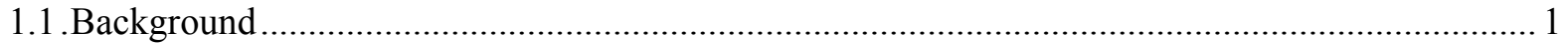

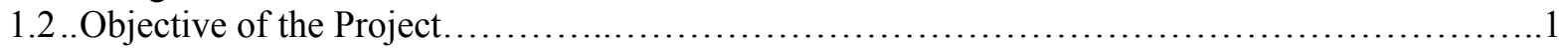

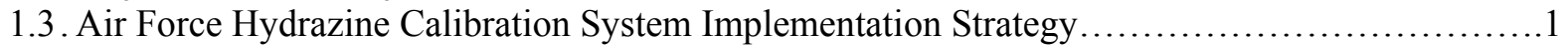

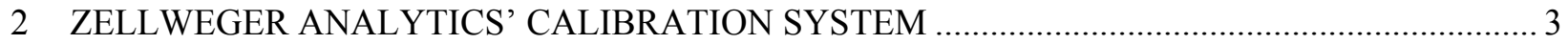

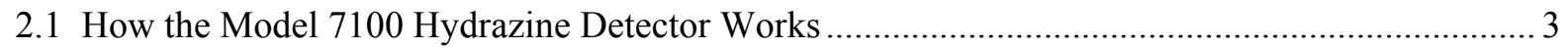

2.2 Current Calibration Method Used by Zellweger Analytics.......................................................... 3

2.2.1 Field Calibration Methods Recommended by ZA ….......................................................... 3

2.2.2 Details of ZA Calibration Procedure .................................................................................. 4

2.3 Uncertainty Analysis of ZA's Calibration Methodology for the MDA 7100_.............................. 7

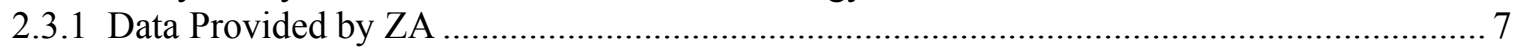

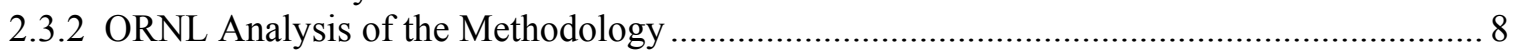

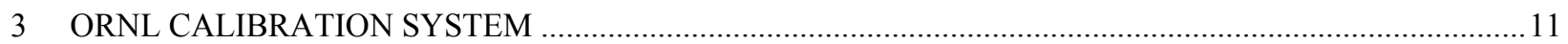

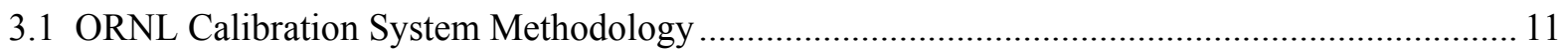

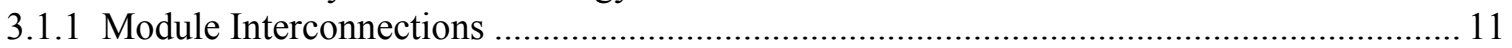

3.2 Uncertainty Analysis of ORNL Calibration Methodology for the MDA 7100 …...................... 13

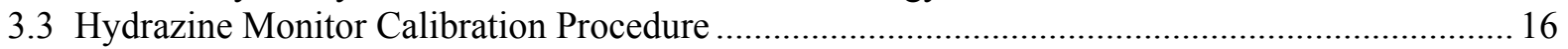

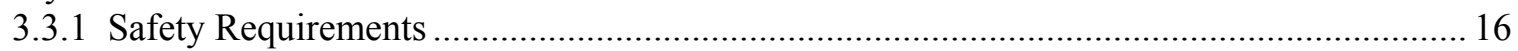





3.3.4 Calibration of the Kintek 491 Gas Generation System Using Coulometric Titration .........26

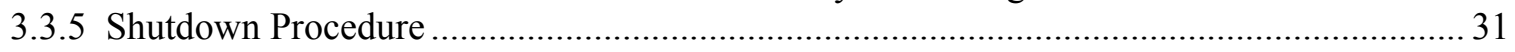

4 VERIFYING GAS CONCENTRATION: COULOMETRIC TITRATION SYSTEM....................... 32

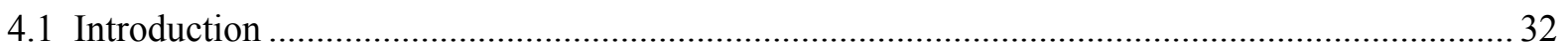

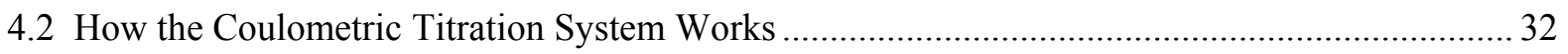

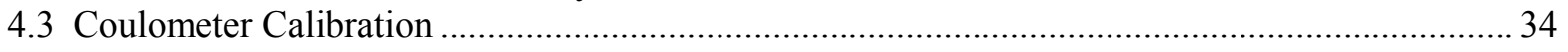

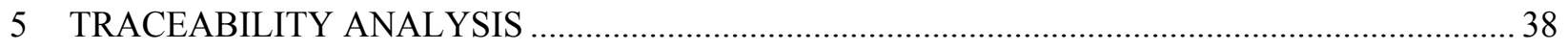

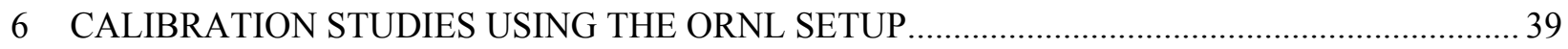

6.1 Calibrating the Kintek 491MB Reference Gas Generation System ........................................... 39

6.2 Calibrating the MDA 7100: Characterization of Relative Humidity Effects .............................. 40

6.3 Calibrating the Interscan 118PQ Sensors Using the Kintek 491MB..................................... 43 


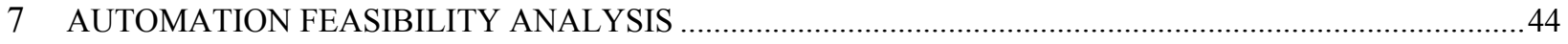

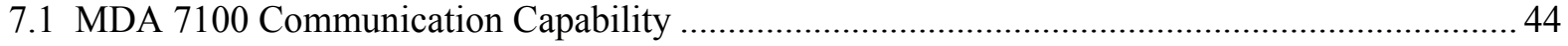

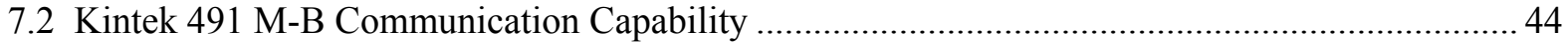

7.3 Recommendations for Automation of Hydrazine Monitor Calibrations ...................................... 44

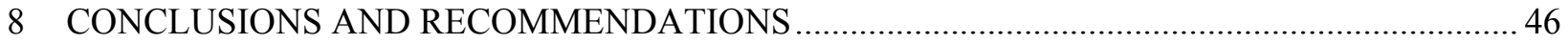

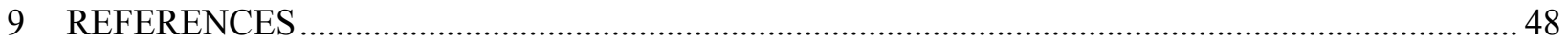

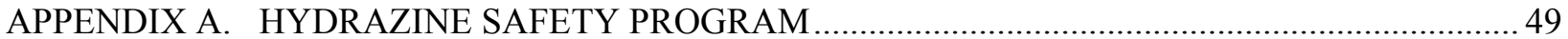



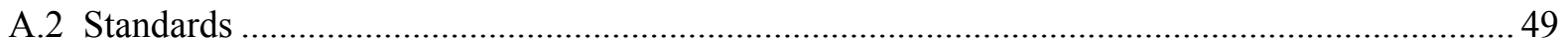

A.3 Worst Case Accident Scenarios in Hydrazine Calibration Laboratory ..................................... 49

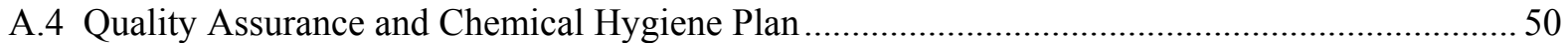

A.5 Hydrazine Detector Calibration Safety Video .......................................................................... 51

APPENDIX B CONTENTS OF SLIDES IN ORNL SAFETY VIDEO ...............................52 


\section{LIST OF FIGURES}

Figure

Page

2.1 Zellweger Analytics’ model MDA 7100 hydrazine monitor .................................................... 4

2.2 Simplified diagram of Zellweger Analytics' hydrazine gas generation/calibration system.......... 5

2.3 Photograph of Zellweger Analytics' hydrazine gas generation/calibration system ..................... 6

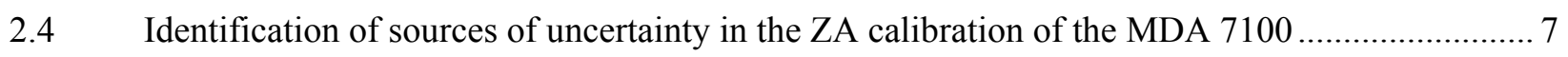

3.1 Simplified flow diagram of the ORNL hydrazine gas generation/calibration system................. 11

3.2 Photograph of ORNL hydrazine gas generation/calibration system. From left to right: Gas mixer module, humidifier module, and interface module. The MDA 7100 sits on the far right, close to gas cylinder

3.3 Identification of sources of uncertainty in the ORNL Kintek-491 M-B-based process for calibration of the MDA 7100 .

3.4 Simplified flow diagram and interconnections of the 491M-B and 491M-HG modules............ 21

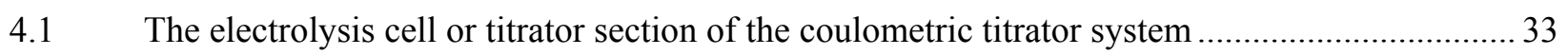

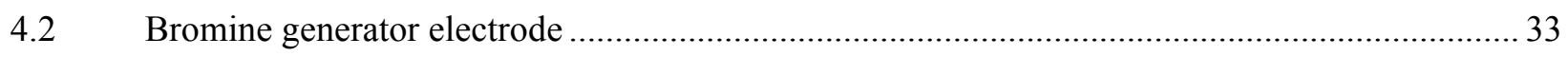



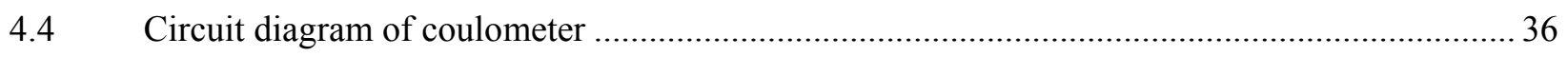

4.5 Laboratory setup of the ORNL coulometric titration system ............................................ 37

4.6 Typical recorder output of a coulometric titration run ....................................................... 37

5.1 Diagram depicting traceability of the gas concentration generated by the Kintek 491 M-B

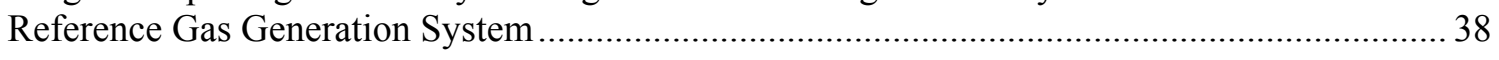

6.1 Determination of the calibration factor $\left(\mathrm{C}_{\mathrm{c}}\right)$ for the Kintek $491 \mathrm{M}-\mathrm{B}$ using the coulometer

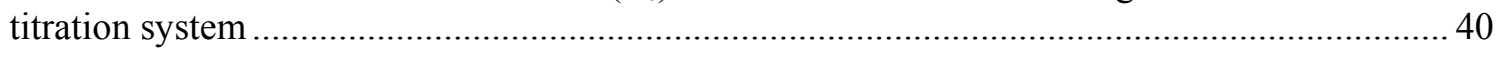

6.2 ORNL relative humidity results compared to the ZA and NASA studies............................. 41

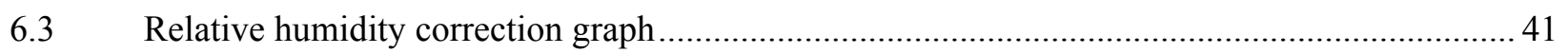

6.4 Comparison of ORNL's humidity-corrected calibration data with corresponding data for the

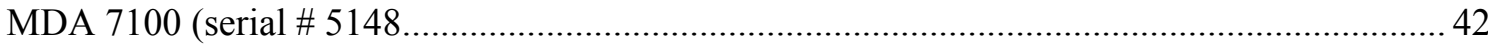

6.5 Comparison of ORNL's humidity-corrected calibration data with corresponding data for the

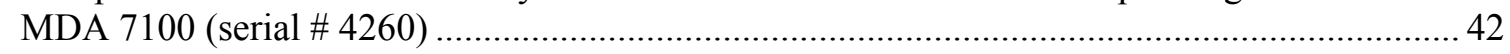

6.6 ORNL calibration of Interscan 4187 hydrazine detector ................................................ 43 


\section{LIST OF TABLES}

Table

Page

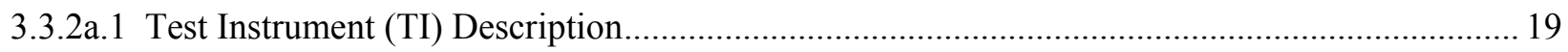

3.3.2a.2 Reference Gas Generation System Description .................................................................. 19

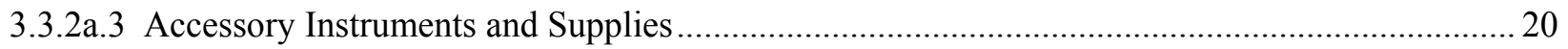

4.1 HP multimeter readings vs coulometer panel meter readings ............................................... 35






\section{ACKNOWLEDGEMENTS}

The Authors wish to acknowledge Dave Madden of the Air Force Metrology Calibration Program (AFMETCAL, OH), Rob Oesch and Joanne Schmitz of Zellweger Analytics (IL), and Rebecca Young of the National Aeronautics and Space Administration (Kennedy Space Center, FL), for the invaluable information and suggestions they provided during the course of this research. Their help, which contributed significantly to the direction and success of this work, is gratefully appreciated. 


\section{ACRONYMS}

ACGIH American Conference of Governmental Industrial Hygienists

$\mathrm{AF}$

AFB

AFOSH

CFR

CRADA

CD

DOE

DUT

EPA

HP

HVAC

KSC

LEL

MSDS

NASA

NIOSH

NIST

OEL

ORNL

OSHA

PEL

PPE

QA

RH

TI

T.O.

TLV

USAF

WFO

ZA
Air Force

Air Force Base

Air Force Occupational Safety and Health

Code of Federal Regulations

Cooperative Research and Development Agreement

Compact Disk

Department of Energy

Device Under Test

Environmental Protection Agency

Hewlett Packard

Heating Ventilating and Air Conditioning

Kennedy Space Center

Lower Explosion Limit

Material Safety Data Sheet

National Aeronautics and Space Administration

National Institute of Occupational Safety and Health

National Institute of Standards and Technology

Occupational Exposure Limit

Oak Ridge National Laboratory

Occupational Safety and Health Administration

Personnel Exposure Limit

Personal Protective Equipment

Quality Assurance

Relative Humidity

Test Instrument

Technical Order

Threshold Limit Value

United States Air Force

Work for Others

Zellweger Analytics 


\section{EXECUTIVE SUMMARY}

This report documents the results of Phase 1 of the Air Force Hydrazine Detector Characterization and Calibration Project. A method for calibrating model MDA 7100 hydrazine detectors in the United States Air Force (AF) inventory has been developed. The calibration system consists of a Kintek 491 reference gas generation system, a humidifier/mixer system which combines the dry reference hydrazine gas with humidified diluent or carrier gas to generate the required humidified reference for calibrations, and a gas sampling interface.

The Kintek reference gas generation system itself is periodically calibrated using an ORNL-constructed coulometric titration system to verify the hydrazine concentration of the sample atmosphere in the interface module. The Kintek reference gas is then used to calibrate the hydrazine monitors. Thus, coulometric titration is only used to periodically assess the performance of the Kintek reference gas generation system, and is not required for hydrazine monitor calibrations. One advantage of using coulometric titration for verifying the concentration of the reference gas is that it is a primary standard (if used for simple solutions), thereby guaranteeing, in principle, that measurements will be traceable to SI units (i.e., to the mole).

The effect of humidity of the reference gas was characterized by using the results of concentrations determined by coulometric titration to develop a humidity correction graph for the Kintek 491 reference gas generation system.

Using this calibration method, calibration uncertainty has been reduced by $50 \%$ compared to the current method used to calibrate hydrazine monitors in the Air Force inventory and calibration time has also been reduced by more than $20 \%$.

Significant findings from studies documented in this report are the following:

1. The Kintek 491 reference gas generation system (generator, humidifier and interface module) can be used to calibrate hydrazine detectors.

2. The Kintek system output concentration is less than the calculated output of the generator alone but can be calibrated as a system by using coulometric titration of gas samples collected with impingers.

3. The calibrated Kintek system output concentration is reproducible even after having been disassembled and moved and reassembled.

4. The uncertainty of the reference gas concentration generated by the Kintek system is less than half the uncertainty of the Zellweger Analytics' (ZA) reference gas concentration and can be easily lowered to one third or less of the ZA method by using lower-uncertainty flow rate or total flow measuring instruments.

5. The largest sources of uncertainty in the current ORNL calibration system are the permeation rate of the permeation tubes and the flow rate of the impinger sampling pump used to collect gas samples for calibrating the Kintek system. Upgrading the measurement equipment, as stated in (4), can reduce both of these.

6. The coulometric titration technique can be used to periodically assess the performance of the Kintek system and determine a suitable recalibration interval. 
7. The Kintek system has been used to calibrate two MDA 7100s and an Interscan 4187 in less than one workday. The system can be upgraded (e.g., by automating it) to provide more calibrations per day.

8. The humidity of both the reference gas and the environment of the Chemcassette affect the MDA 7100 hydrazine detector's readings. However, ORNL believes that the environmental effect is less significant than the effect of the reference gas humidity.

9. The ORNL calibration method based on the Kintek $491 \mathrm{M}-\mathrm{B}$ gas standard can correct for the effect of the humidity of the reference gas to produce the same calibration as that of ZA's. Zellweger Analytics' calibrations are typically performed at $45 \%-55 \%$ relative humidity.

10. Tests using the Interscan 4187 showed that the instrument was not accurate in its lower $(0-100 \mathrm{ppb})$ range. Subsequent discussions with Kennedy Space Center (KSC) personnel also indicated that the Interscan units were not reproducible when new sensors were used. KSC had discovered that the Interscan units read incorrectly on the low range because of the presence of carbon dioxide. ORNL did not test the carbon dioxide effect, but it was found that the units did not read zero when a test gas containing no hydrazine was sampled. According to the KSC personnel that ORNL had these discussions with, NASA is phasing out the use of these Interscan detectors.

Based on the findings identified from these studies, the following recommendations are suggested:

a) The coulometric calibration procedure should be used to perform additional calibrations of the Kintek system to establish a base set of data to be used in statistical process control of it.

b) The system should be used to calibrate and recalibrate the ZA 7100's and other hydrazine detectors to establish a baseline set of data to be used in statistical process control and establish the methods for detecting the need for recalibration and calibration recall intervals of each type of detector.

c) Automating the data collection and analysis as well as the reporting procedures should further reduce the time per calibration and turnaround time to calibrate and instrument.

d) The calibration procedure Technical Order should be implemented as a fully automated interactive checklist, data acquisition and analysis system. This will reduce the need to repeat calibrations because something that needed to be done was omitted or done incorrectly.

e) The development of a miniaturized version of the coulometric titrator, which could be placed in-line between the reference gas generation system and the detector, should be considered. Such a system is likely to have much better resolution, reliability, and much lower uncertainty than currently available hydrazine detectors/standards. 


\section{INTRODUCTION}

\subsection{Background}

Hydrazine $\left(\mathrm{N}_{2} \mathrm{H}_{4}\right)$, monomethyl hydrazine $(\mathrm{MMH})$, and unsymmetrical dimethyl hydrazine are used as rocket propellants, as an antioxidant in industrial processes, and in the production of pesticides and pharmaceuticals. All these hydrazines are strong reducing agents, highly reactive, toxic, and suspect carcinogens. Hydrazine vapor in air is flammable at 4.7 to $100 \%$ hydrazine by volume. The personnel exposure limit (Part 1910 of Title 29 of the Code of Federal Regulations (29 CFR 1910.1000)) is 1 ppm $\left(1.3 \mathrm{mg} / \mathrm{m}^{3}\right)$. The American Conference of Governmental Industrial Hygienists (ACGIH) has recommended $10 \mathrm{ppb}\left(0.013 \mathrm{mg} / \mathrm{m}^{3}\right)$ as the threshold limit value for occupational exposures to hydrazine (i.e., $\mathrm{N}_{2} \mathrm{H}_{4}$ ) in workplace air. Since the Air Force typically invokes the most stringent levels (see Air Force Occupational Safety, Fire Prevention and Health (AFOSH) Std 48-8), this means the ACGIH's TLV is to be the value used to set the Air Force's Occupational Exposure Limits (OEL). At such small exposure limits, the accuracy and uncertainty of the calibration system becomes very important.

\subsection{Objective of the Project}

A number of hydrazine monitors, including the MDA 7100 manufactured by Zellweger Analytics (ZA) and the Interscan model 118P hydrazine sensors manufactured by Interscan, are in use by the United States Air Force (USAF), of which recalibrations are performed at 2-year intervals. The studies documented in this report were performed by Oak Ridge National Laboratory (ORNL) for the USAF with the following objectives:

(1) develop an improved calibration method for the hydrazine monitors, thereby reducing the uncertainty associated with these calibrations, as well as reducing the calibration time and improving the turn-around time;

(2) once a calibration procedure has been developed, ensure a smooth transfer of the technology to the Air Force.

\subsection{Air Force Hydrazine Detector Calibration System Implementation Strategy}

To meet the objectives of the work, the Air Force Hydrazine Detector Characterization and Calibration Project was divided into 5 phases as follows:

PHASE 1: New Calibration System Implemented at ORNL Using AF Standards and Requirements This phase involved an analysis of the calibration method currently used by ZA to identify ways of improving the procedure.

\section{PHASE 2: Automation of Calibration Method to Improve Performance and Reduce Cost Per Calibration}

This phase involves first performing more calibration runs using the method developed in phase 1 in order to establish a base set of data to be used in statistical process control of it. An Excel spreadsheet will also 
be developed and automated to perform the data analysis and create the calibration certificates. Finally, a web-based calibration procedure and training video will be developed.

\section{PHASE 3: ORNL Calibration of Air Force Hydrazine Detectors}

The Air Force would like to have the option of eventually having all hydrazine monitor calibrations performed at ORNL on a permanent basis. Therefore Air Force hydrazine monitors will be brought to ORNL for calibration during this phase.

\section{PHASE 4: Duplication of ORNL Setup at Hill AFB and Vandenberg AFB}

This phase documents the tasks to be performed if the option of transferring the ORNL Calibration System to the AF is chosen (i.e., instead of having ORNL perform detector calibrations for the AF).

\section{PHASE 5: Review of Calibration Support of Additional AF Hydrazine Sensors}

While the focus of this project is to develop an improved calibration methodology for model 7100 hydrazine monitors, several other types of hydrazine sensors from other manufactures are also available in the AF inventory. During Phase 5, the various other hydrazine sensors will be identified and the AF will be provided with a report detailing the optimum method of providing calibration support for these sensors.

The studies documented in this report constitutes phase 1 of the Air Force Hydrazine Detector Characterization and Calibration project. 


\section{ZELLWEGER ANALYTICS' CALIBRATION SYSTEM}

\subsection{How the Model 7100 Hydrazine Detector Works}

The MDA 7100 hydrazine monitor (Figure 3.1) determines the concentration of a test gas by exposing a chemcassette tape to a sample of the test gas. The chemcassette tape reacts with the test gas and changes color in proportion to the concentration of the gas. The 7100's built-in firmware has concentration versus optical density response curves that are used to calculate the gas concentration and then record and/or display it.

\subsection{Current Calibration Method Used by Zellweger Analytics}

\subsubsection{Field Calibration Methods Recommended by ZA}

Field calibrations of the MDA 7100 can be performed in three different ways; an optics calibration method, a dynamic calibration method, or a manual calibration method.

The optics calibration uses a stain card containing two rectangular color blocks. When the card is used in the optics calibration, it returns the monitor's ability to interpret differences in stain intensity to the same level that it was on the day the unit was calibrated by the manufacturer. It is typically performed whenever a fresh Chemcassette Detection Tape is installed (the Chemcassette Detection Tape should not be in place when the optics calibration is performed).

A stain card is made of high-pressure plastic laminated material with excellent color stability. One of the rectangular color blocks represents the color stain produced when there is no hydrazine (Zero value), and the other represents the color produced at the maximum concentration (Span) of the instrument during the original dynamic calibration. Calibration consists of inserting the stain card into the instrument to obtain new values for the Zero and Span. The instrument uses these readings to calculate a new "Q" factor given by:

$\mathbf{Q}=[($ Card Span $)-($ Card Zero $)] /[($ Actual Span $)-($ Actual Zero $)]$

That is,

$$
Q=\frac{S_{s}-S_{z}}{A_{s}-A_{z}}
$$

where

Card Span $\left(\mathbf{S}_{\mathbf{s}}\right)$ and Card Zero $\left(\mathbf{S}_{\mathbf{z}}\right)$ are the readings obtained during the original calibration (written on the stain card); and Actual Span $\left(\mathbf{A}_{\mathbf{s}}\right)$ and Actual Zero $\left(\mathbf{A}_{\mathbf{z}}\right)$ are the new span and zero readings

Dynamic calibration is performed by using a test gas of known concentration. The Chemcassette Tape must be in place when performing a dynamic gas calibration. The calibration gas is first connected to the instrument sampling port ready for monitoring. Calibration is performed by entering the concentration value of the calibration gas into the instrument. The instrument is then commanded to monitor the calibration gas. It uses the value it reads to calculate a calibration factor $\mathbf{K}$ as follows: 
$K=[($ Concentration Value of Calibration Gas) $/($ Actual Model 7100 Reading $)]$

That is,

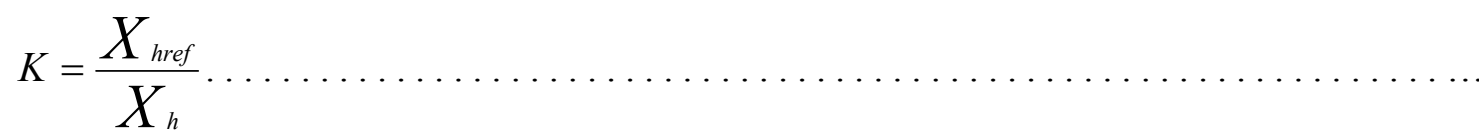

Manual calibration of the hydrazine monitor is essentially a dynamic calibration performed when the concentration of the test gas is not known. It allows one to manually enter the " $\mathrm{K}$ " value once the concentration of the test gas has been independently verified. Since an optics (stain card) calibration is also performed during a manual calibration, a new "Q" factor is also calculated by the instrument during manual calibration. This is the method used by the manufacturer to perform calibrations when equipment is sent to them by the Air Force.

\subsubsection{Details of ZA Calibration Procedure}

Since the optical density measurements are critical to the measured gas concentration it is essential to ensure that the 7100's lamp and photocell detector are properly adjusted within tolerances which will ensure that the optical density measurements are on the same response curve as the one in the firmware. Therefore, the first part of the ZA setup and calibration procedure is adjustment of the 7100 to be calibrated [device under test (DUT)] to match the current 7100 operating specifications. The DUT and a 7100 that has already been adjusted to current operating specifications and calibrated (called the grandfather 7100) are turned on and allowed to warm up for several hours. This is to allow their lamps to reach the correct temperature and produce the correct brightness and illumination.

The DUT's alarm conditions are simulated and the alarms are checked for correct operation. Then the DUT's lamp voltage is measured and adjusted to be within the required uncertainty of the specified voltage. Next the photocell detector is tested using a blank cal card (stain card) in place of the chemcassette. The position of the lamp is then adjusted until the photocell readings are within the required range.

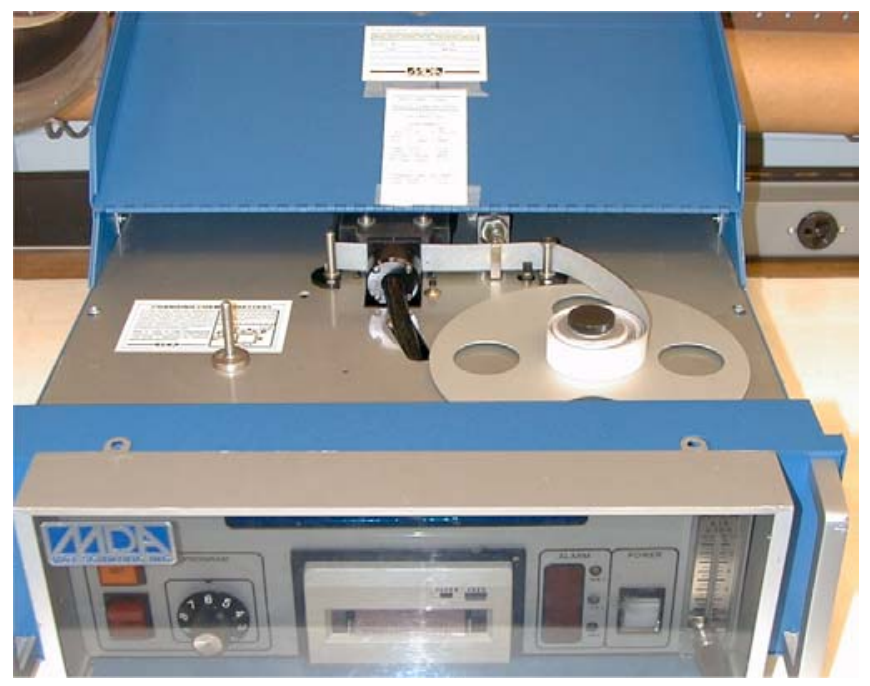

Fig. 2.1. Zellweger Analytics' model MDA 7100 hydrazine monitor 
Before the DUT is calibrated using reference gas concentrations, the gas sampling system must be adjusted to ensure that it is operating within the required leak and flow rate limits. This is done to ensure that chemical reaction flow conditions between the gas sample and the chemcassette tape are the same as the conditions that existed to obtain the test gas concentration versus optical density response curves in the firmware of the 7100. This is accomplished by first comparing the flow indicated by the 7100's rotameter to a calibrated rotameter connected to the sample port. Then the calibrated rotameter is connected to the 7100's exhaust and the flow indicated by the 7100's rotameter is again compared to the calibrated rotameter. If the two rotameter readings do not agree, the sampling pump must be fixed. Finally, with the calibrated rotameter still connected to the 7100's exhaust and the sampling pump running, the sample port is plugged. This should result in the calibrated rotameter indicating close enough to zero flow to stay within the require leak limits of the 7100.

The DUT 7100 and a grandfather 7100 (the grandfather 7100 is another 7100 which as been recently calibrated and adjusted to be operating according to the ZA specifications) are now simultaneously used to measure the concentration of the sample atmosphere containing the reference gas at a reference concentration within the range of the DUT and grandfather 7100s. This is then repeated for two or three additional reference gas concentrations within the range of DUT and grandfather 7100s.

For hydrazine calibrations the sample atmosphere is a combination of hydrazine vapor in humidified nitrogen. The sample atmosphere is generated by flowing humidified nitrogen through the hydrazine vapor phase of a glass bulb that is partially filled with liquid hydrazine and maintained at constant temperature in a constant temperature bath (see Figures 3.2 and 3.3). Adjusting the flow rate of the humidified nitrogen through the hydrazine vapor controls the hydrazine concentration. The sample atmosphere must be kept within a specific range of relative humidity and temperature. This is done to ensure that the relative humidity and temperature of the chemical reaction between the gas sample and the chemcassette tape are within acceptable limits of the relative humidity and temperature that existed to obtain the test gas concentration versus optical density response curves in the firmware of the 7100 .

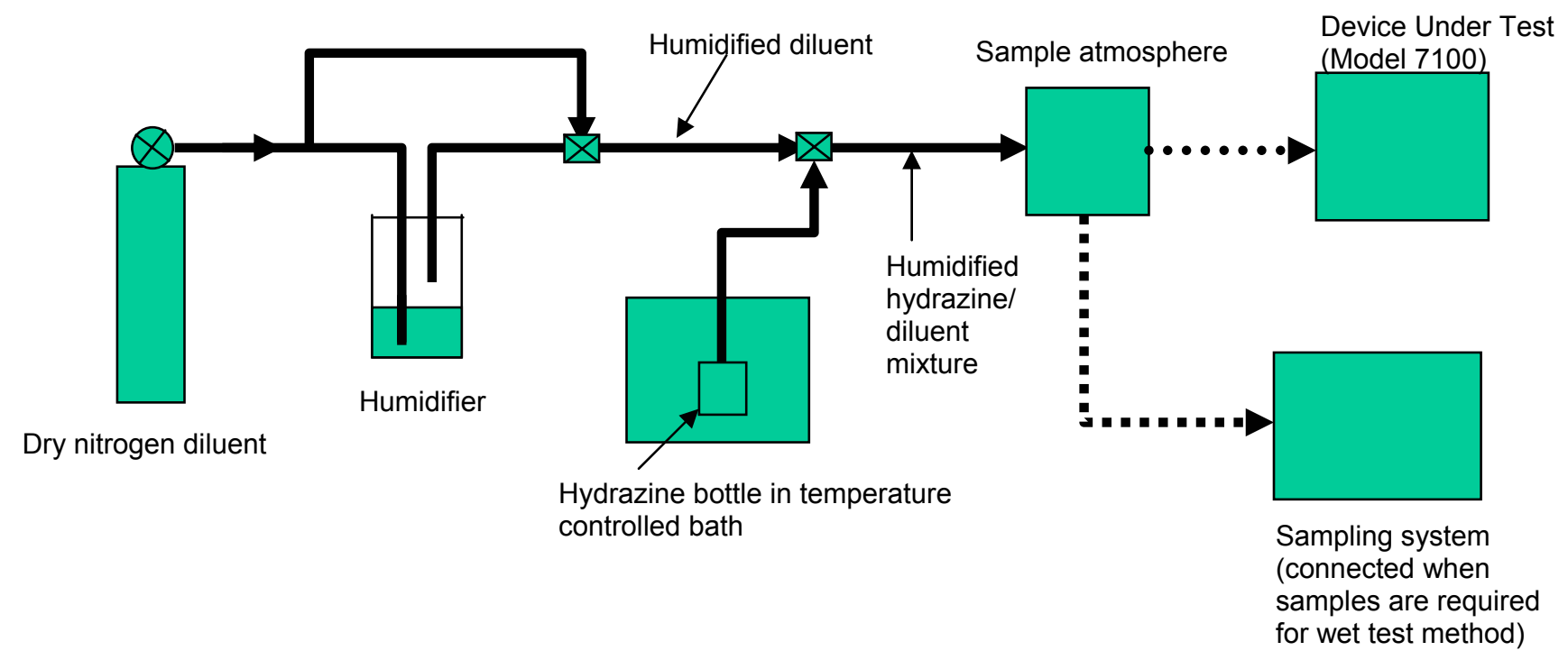

Fig. 2.2. Simplified diagram of Zellweger Analytics' hydrazine gas generation/calibration system. 




Fig. 2.3. Photograph of Zellweger Analytics' hydrazine gas generation/calibration system.

Impinger samples of the atmosphere are collected to determine the hydrazine concentration of the sample atmosphere. The impinger samples are collected by pumping a measured flow of the reference gas from the sample atmosphere through an impinger for a measured time interval. The amount of hydrazine in the impinger samples is determined by using a wet chemical analysis procedure for hydrazine and spectrophotometric measurements. The concentration of the hydrazine in the sample atmosphere is then calculated from these results. This is done for each of the different sample atmosphere concentrations used in the calibration of the 7100 .

Starting with the largest concentration sample atmosphere, the sample atmosphere is separately connected to the sample ports of both the DUT 7100 and the grandfather 7100 and they are used to measure the hydrazine concentration of the sample atmosphere. These measurements are compared and the reading of the DUT 7100 is adjusted, if necessary, using its span adjustment to be within plus or minus $5 \%$ of the grandfather 7100. The concentration of the sample atmosphere is lowered and the process above is repeated. The concentration of the sample atmosphere is lowered again and if the DUT 7100 does not read within plus or minus $5 \%$ of the grandfather 7100 it is rejected as no longer able to be calibrated without repair. If the DUT is still within the plus or minus $5 \%$ of the grandfather this process may be repeated for one more lower concentration if needed.

When the calibration above is completed successfully, an optics calibration using the stain card for this specific DUT 7100 is performed. This stain card has a strip on the card with a color used to set the zero and a strip on the card with a color used to determine the span for hydrazine measurements. The chemcassette tape is removed and the stain card zero color strip is inserted in the optics block. The zero is then adjusted to the required value for hydrazine measurement. Next the stain card is removed and reinserted with its span color strip in the optics block and the span value shown on the display is recorded. The values for the zero and span are then entered as the ZERO and SPAN values requested by the 7100 when placed in the optics calibration mode. 
Finally, the millivolt per count reading of the DUT 7100 is checked to ensure that it is within the required range for hydrazine.

\subsection{Uncertainty Analysis of Zellweger Analytics' Calibration Methodology for the MDA 7100}

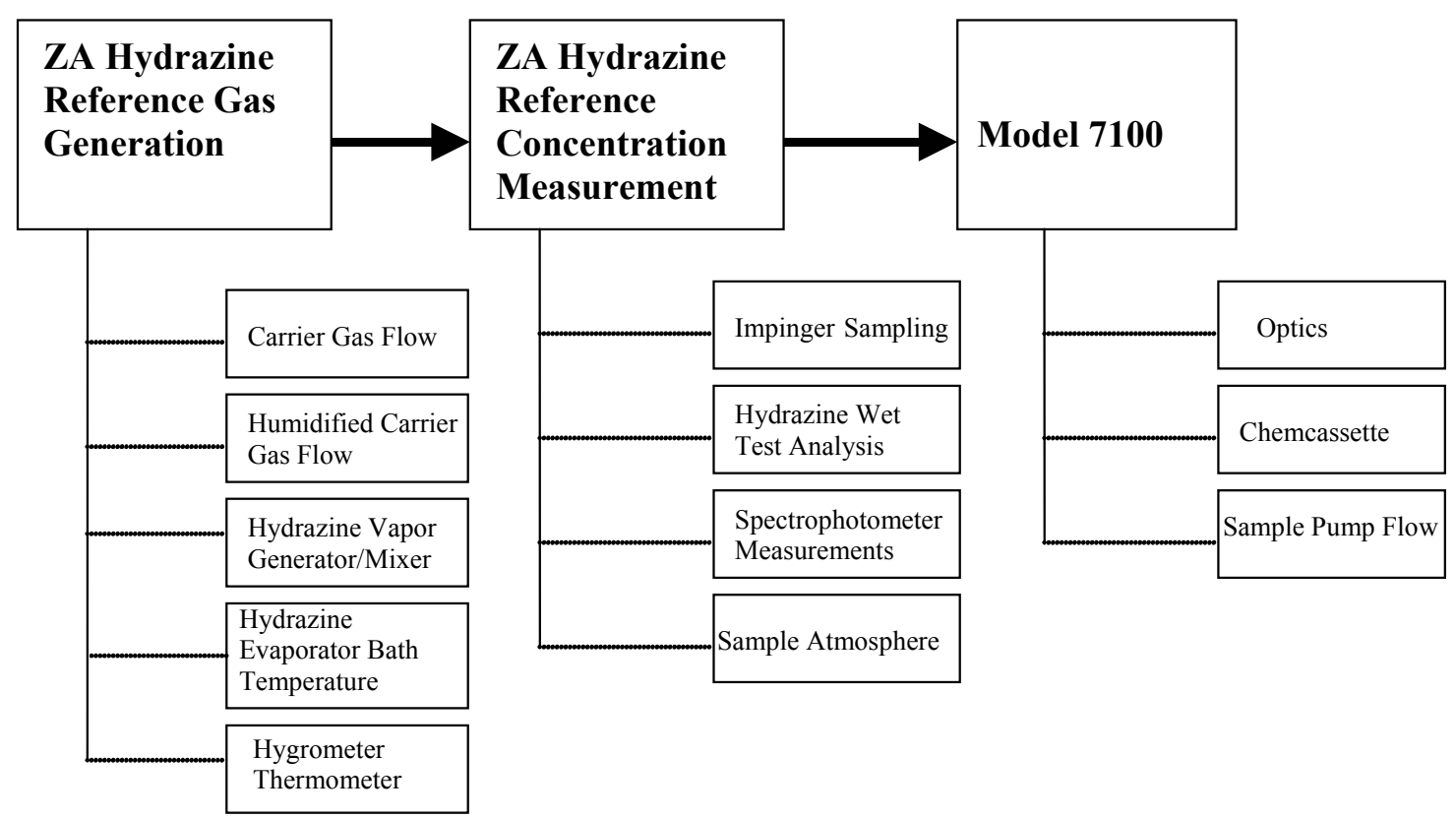

Figure 2.4 Identification of sources of uncertainty in the ZA calibration of the MDA 7100 .

ORNL performed an uncertainty analysis of the ZA calibration method for the 7100 hydrazine detector. A summary is provided below. For completeness, data provided by ZA, which was used as the basis for the analysis, is also reproduced here:

\subsubsection{Data Provided by Zellweger Analytics}

\section{Chemcassette}

The Hydrazine Chemcassette has a manufacturing specification of $+/-10 \%$.

\section{Optics}

The optics calibration uses a stain card containing two rectangular color blocks. When the card is used in the optics calibration, it returns the monitor's ability to interpret differences in stain intensity to the same level that it was on the day the unit was calibrated at the ZA laboratory. The uncertainty of the optics calibration depends greatly on the stability of the color blocks. ZA has not yet provided ORNL investigators with values for the color blocks' uncertainties. However, these color blocks are reported to have been selected for their excellent light stability and durability. Cognizant ZA experts indicate that because of this inherent stability, they expect negligible deterioration under normal use. They recommend that cleaning procedures listed in the user's manual should be followed. Also, it should be realized that visible scratches will adversely affect the optics calibration. ZA can replace the card, if needed. A new stain card is provided with the 7100 whenever it is sent to ZA for recalibration.

\section{Flow meter}

The 7100 flow meter, which controls the flow through the Chemcassette tape, has a manufacturer specification of $\pm 4 \%$ of full scale. 


\section{Hydrazine Concentration Verification}

The ZA hydrazine concentration verification methodology employs a wet test method, which has been in use since the development of the Hydrazine Chemcassette and the current hydrazine, monitors. The original statistical data on the method was unavailable from ZA. However, cognizant ZA personnel indicate that it is similar to the NIOSH wet test method (\#3503) as referenced in "NIOSH Pocket Guide to Chemical Hazards - 1997", which has an accuracy of $+/-17.1 \%$. Both methods use a spectrophotometer and the same complexing reagent. However, there are differences in these two methods that could affect accuracy. NIOSH \#3503 uses a micropipette volume of hydrazine (reactivity with oxygen) for calibration. The ZA method uses a hydrazine derivative, a solid that does not have the oxygen reactivity of hydrazine and which can be accurately weighed on an analytical balance for calibration. ZA has indicated that they expect a better degree of accuracy with their method.

Any uncertainty in equipment used in either of these methods would be part of the accuracy of the method. That part of the method accuracy due to equipment would include the following:

\section{Spectrophotometer}

The hydrazine samples are compared to hydrazine standards that are both run on the same spectrophotometer. This helps to minimize uncertainties.

\section{Pump}

The sample collection pump has a constant flow specification of $+/-5 \%$ of the initial set point. To minimize any change in flow during sampling, the ZA method requires measurement of the actual flow before and after the sampling using a bubble flow cell, which has a specification of $+/-1 \%$ of reading.

\section{General Comments on Hydrazine Monitoring by ZA Personnel}

There are a number of problems associated with working with hydrazine. First, any changes to the generating system (either humidity or concentration) will require a stabilization period. The length of time would depend on the degree of the change. Second, the hydrazines have a propensity for both chemisorption and physical adsorption by the tubing, fittings, and other materials of the calibration system. To ensure the best calibration of any hydrazine monitor, sufficient time must be allowed to condition the monitor prior to any calibration.

\subsubsection{ORNL Analysis of the ZA Calibration Methodology}

The gas concentration read by the 7100 is determined by the response of its photodetector to the light reflected to it from the spot produced on the chemcassette when it reacts with the gas mixture containing the hydrazine. Therefore, the location and alignment of the photodetector and the illumination lamp with respect to the chemcassette must be carefully maintained to ensure repeatability of this response. The intensity of the illumination lamp must also be carefully maintained within specified limits.

ZA did not provide ORNL with the equations used by the 7100 to print out the measured concentration. However, based on information provided by ZA describing the operation of the 7100, ORNL has developed an equation that relates the concentration printed by the 7100 to calibration parameters and conversion factors of the 7100 . In particular, the concentration printed by the 7100 is calculated by the equations shown below: 


$$
X_{h}=\frac{K N}{Q\left(A_{s}-A_{z}\right)} R_{h}+Z_{h}
$$

with

$$
Q=\frac{S_{s}-S_{z}}{A_{s}-A_{z}}
$$

and

$$
K=\frac{X_{\text {href }}}{X_{h}}
$$

where:

$\mathrm{X}_{\mathrm{h}}$ is the hydrazine concentration reading of the $7100 \mathrm{in} \mathrm{ppb}$

$\mathrm{R}_{\mathrm{h}}$ is the hydrazine concentration range of the $7100 \mathrm{in} \mathrm{ppb}$

$\mathrm{Z}_{\mathrm{h}}$ is the lowest detectable hydrazine concentration of the $7100 \mathrm{in} \mathrm{ppb}$

$\mathrm{Q}$ is the stain card calibration factor for the stain card optics calibration of the 7100

$\mathrm{N}$ is the photodetector output in counts

$\mathrm{A}_{\mathrm{s}}$ is the actual stain card span color chip reading at the time of the stain card optics calibration

$\mathrm{A}_{\mathrm{z}}$ is the actual stain card zero color chip reading at the time of the stain card optics calibration

$\mathrm{S}_{\mathrm{s}}$ is the stain card span color chip reading at the time of the stain card optics calibration stored in firmware

$\mathrm{S}_{\mathrm{z}}$ is the stain card zero color chip reading at the time of the stain card optics calibration stored in firmware

$\mathrm{X}_{\text {href }}$ is the reference gas hydrazine concentration used to calibrate the 7100 analyzed by a chemical wet test

$\mathrm{K}$ is the calibration factor obtained by comparing the concentration $\left(\mathrm{X}_{\mathrm{h}}\right)$ read by the 7100 to the concentration $\left(\mathrm{X}_{\mathrm{href}}\right)$ found with the chemical wet test

Combining these equations to determine the uncertainty of $X_{h}$ results in:

$$
X_{h}^{2}=\frac{X_{\text {href }} N}{Q\left(A_{s}-A_{z}\right)} R_{h}+Z_{h} X_{h}
$$

Assuming $Z_{h} X_{h}$ is negligible $\left(Z_{h} \approx 0\right)$, then

$$
X_{h}=\sqrt{\frac{X_{\text {href }} N}{Q\left(A_{s}-A_{z}\right)} R_{h}}
$$

Let

$$
W=\frac{X_{\text {href }} N}{Q\left(A_{s}-A_{z}\right)} R_{h}
$$

then

$$
X_{h}=\sqrt{W}
$$


Using the uncertainty analysis methodology described by NIST at

http://physics.nist.gov/cuu/Uncertainty/combination.html and assuming normal distributions and no correlation between input estimates and input quantities,

let

$$
u_{W}=\sqrt{u_{X_{\text {href }}}^{2}+u_{N}^{2}+u_{Q}^{2}+u_{A_{x}}^{2}+u_{A_{z}}^{2}+u_{R_{h}}^{2}}
$$

and

$$
u_{X_{h}}=\frac{1}{2} u_{W}
$$

where

where $u_{w}$ and $u_{\boldsymbol{X} \boldsymbol{h}}$ are the uncertainties of $w$ and $\boldsymbol{X}_{\mathrm{h}}$ respectively. The variable $u_{\boldsymbol{X} \boldsymbol{h}}$ is the desired uncertainty.

The ZA 970539 wet test method used to measure $\mathrm{X}_{\text {href }}$ (the hydrazine concentration of the reference gas) is based on the NIOSH 3503 wet test method. The NIOSH 3503 wet test method states an uncertainty of $17.1 \%$. We used the NIOSH number of $17.1 \%$ for the uncertainty of $X_{\text {href }}$ because ZA did not provide ORNL with an uncertainty for the ZA wet test method.

The uncertainty in $\mathrm{N}$ is $10 \%$ which is the combination of the $10 \%$ uncertainty in the optical density of the color spot produced on the chemcassette and uncertainty in the optics system which measures the optical density of the spot. The uncertainty of the optics block system is negligible compared to the uncertainty in the optical density of the color spot produced on the chemcassette.

The uncertainties in $\mathrm{Q}, \mathrm{R}_{\mathrm{h}}, \mathrm{Z}_{\mathrm{h}}, \mathrm{A}_{\mathrm{s}}$, and $\mathrm{A}_{\mathrm{z}}$ are all less than $1 \%$ and have a negligible contribution to the uncertainty in $\mathrm{X}_{\mathrm{h}}$

Therefore the combined uncertainty for $X_{h}$ (the 7100 's measurement of hydrazine concentration) is $9.9 \%$.

This uncertainty applies only to a 7100 that has been calibrated using ZA's calibration procedure CAL008 to ensure that the 7100 is being operated correctly and is itself operating according to its specifications so that the uncertainties treated as negligible are in fact negligible. 


\section{ORNL CALIBRATION SYSTEM}

\subsection{ORNL Calibration System Methodology}

\subsubsection{Module Interconnections}

The ORNL calibration system employs a Kintek model 491M-B base module connected to a Kintek 491M- HG humidifier module and a Kintek 491-IM gas sampling interface module. Figure 3.1 shows a schematic of the system. This generator system produces a reference gas with the desired gas concentration and humidity to be used in calibrating gas detectors. The 491 system is designed so that the dilution flow used to calculate the mixture concentration is taken from a single measurement. The 491MHG humidification module gets its dilution gas supply from the base module (491 M-B).

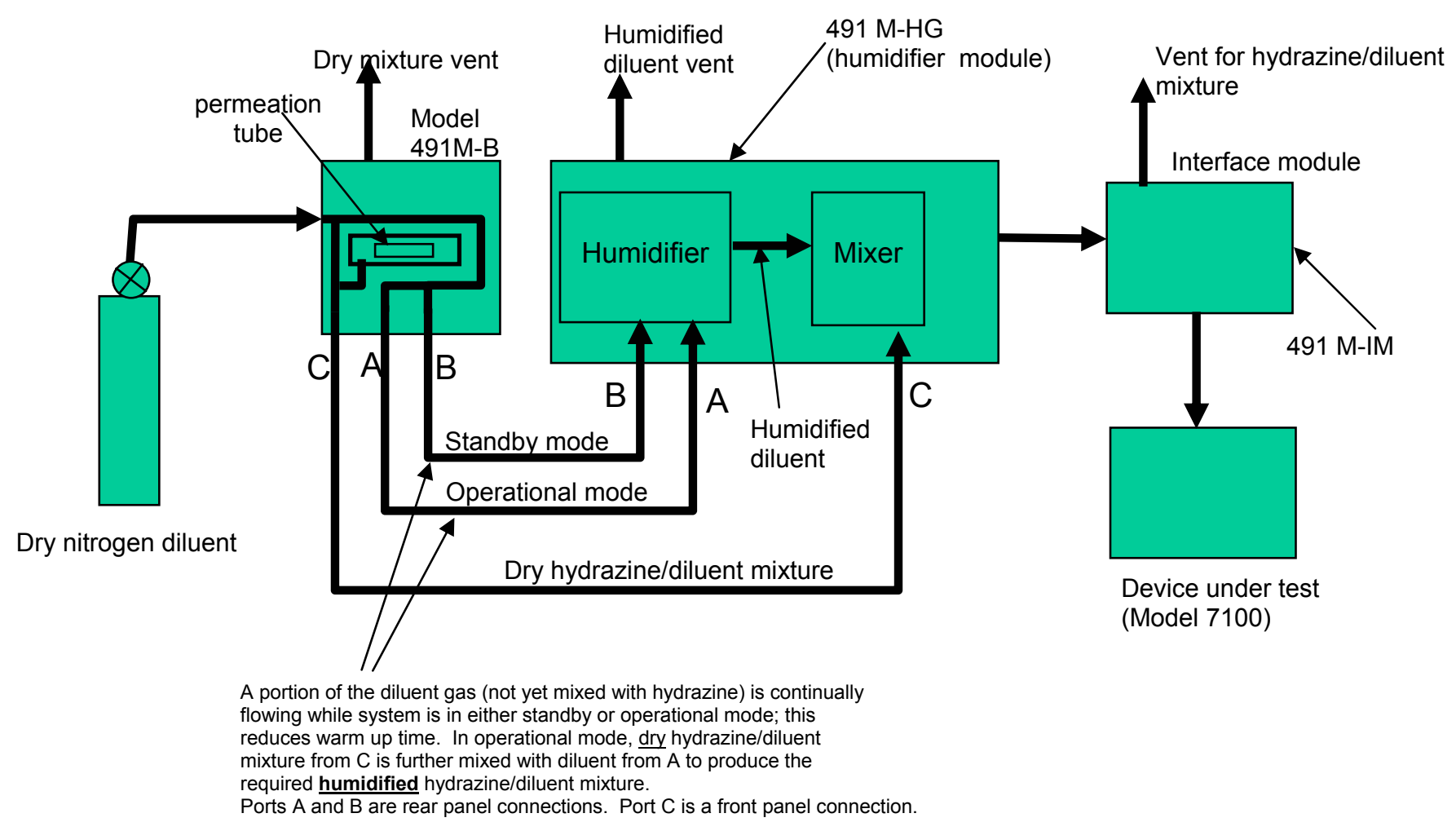

Fig. 3.1 Simplified flow diagram of the ORNL hydrazine gas generation/calibration system.

A photograph of the gas generation system is also shown in Fig. 3.2. A carrier (dilution) gas source is connected to the $491 \mathrm{M}-\mathrm{B}$. Gas entering this module is immediately pressure regulated to $50 \mathrm{psig}$. The dilution flow then splits into 3 parts. One part goes to the system flow meter and serves as the main dilution flow. The second part is used as "standby" flow through the permeation oven to maintain equilibration when the system is in the ZERO or STANDBY mode. The third portion is connected to port "B" at the rear of the module, and is used as standby flow for accessory modules.

The main dilution flow (first part) passes through the system flow meter and again divides into three (3) parts. One part goes to the main dilution flow controller and becomes the "zero" flow. The second part 


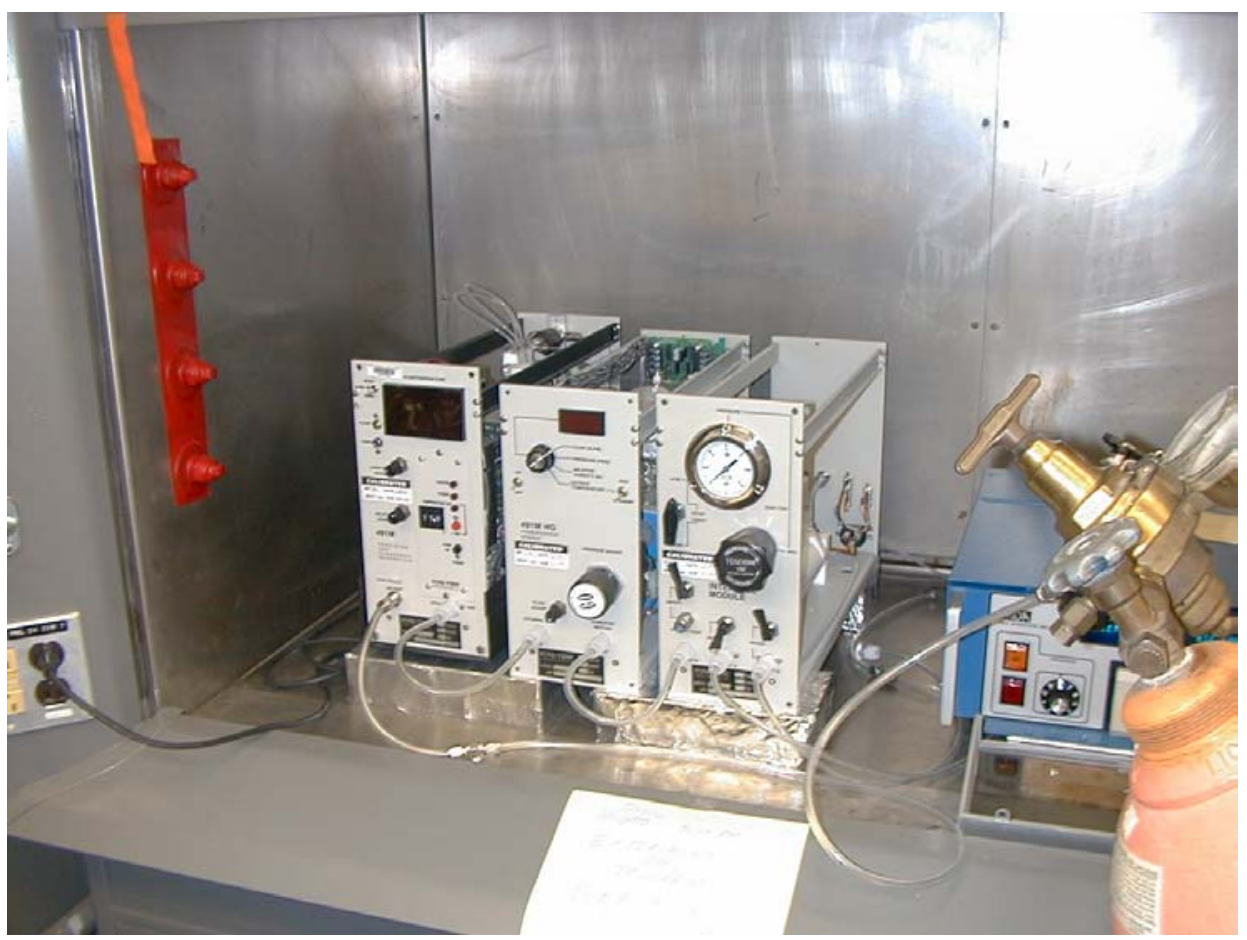

Fig. 3.2. Photograph of ORNL hydrazine gas generation/calibration system. From left to right: Gas mixer module, humidifier module, and interface module. The MDA 7100 sits on the far right, close to the gas cylinder.

becomes the permeate "carrier flow" in the "SPAN" mode. The third part is connected to port "A" on the rear panel and is saturated with moisture in the $491 \mathrm{M}-\mathrm{HG}$.

The 491 M-HG gets its flow from either port "A" (in the $\boldsymbol{R} \boldsymbol{U N}$ mode) or port "B" (in the "STANDBY" mode) on the rear panel. Diluent entering from either port passes through the humidification flow controller, preheater, and saturator. In the RUN mode the humidified gas flow is indicated on the front panel meter of the $491 \mathrm{M}-\mathrm{HG}$. In the $\boldsymbol{S T A N D B Y}$ mode, the flow remains the same as in the $\boldsymbol{R} \boldsymbol{U} \boldsymbol{N}$ mode, but the meter will read "ZERO" since no humidified diluent is being added to the mixture.

Zero or Span (Zero plus Carrier and Permeate) flow from the $491 \mathrm{M}-\mathrm{B}$ enters the $491 \mathrm{M}-\mathrm{HG}$ at the front panel and mixes with the water saturated humidifier flow. The final mixture then passes over a relative humidity (RH) sensor and leaves the system as a humidified gas standard.

In this flow scheme the total dilution flow is indicated on the front panel of the $491 \mathrm{M}-\mathrm{B}$. To adjust the humidity level, the Zero flow in both the $491 \mathrm{M}-\mathrm{B}$ and humidifier are independently adjusted, but the total flow is always indicated on the $491 \mathrm{M}-\mathrm{B}$ 


\subsection{Uncertainty Analysis of ORNL Calibration Methodology for the MDA 7100}

Figure 3.3 represents the ORNL Kintek 491 M-B based process for calibration of the MDA 7100.

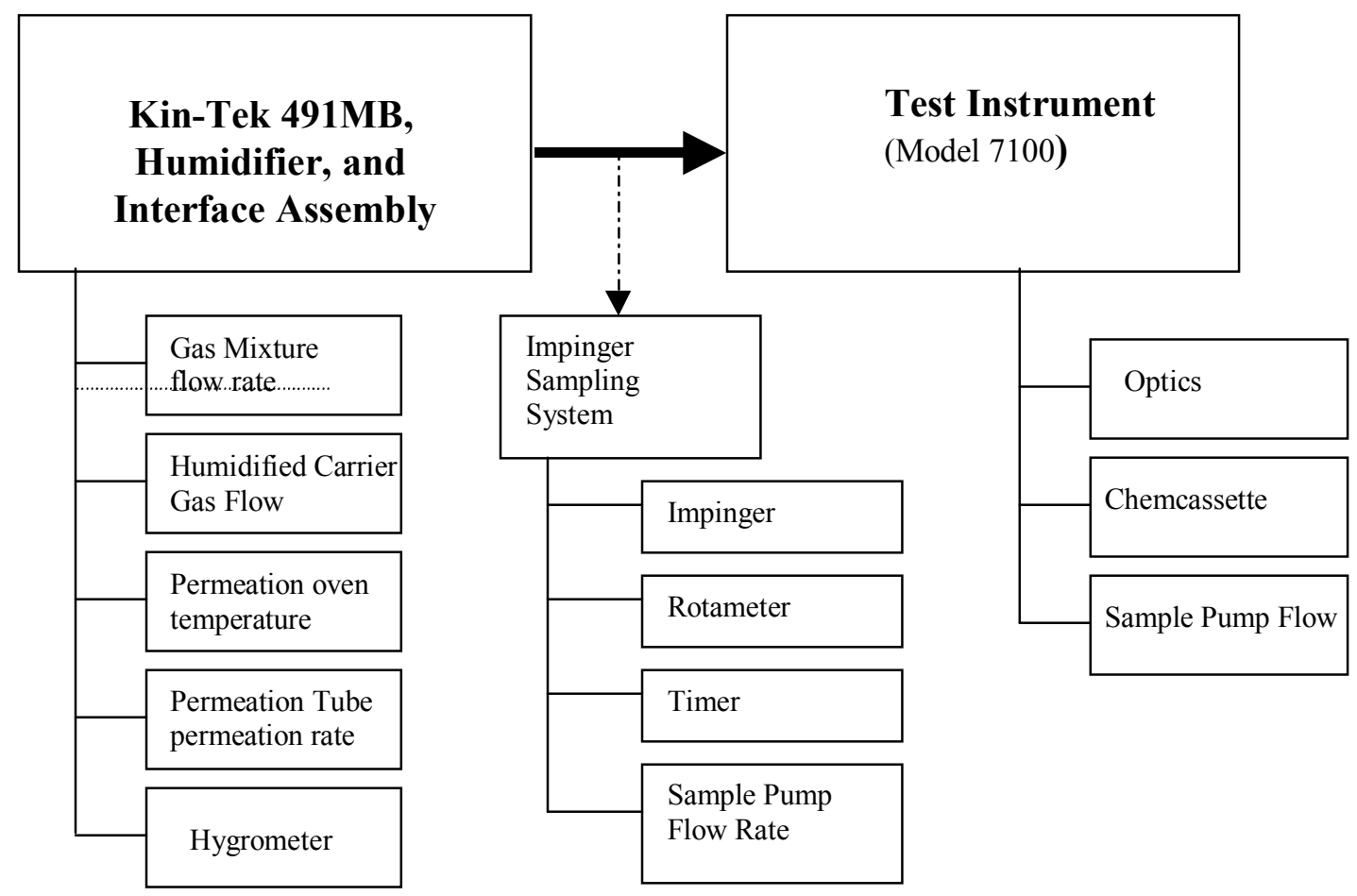

Figure 3.3 Identification of sources of uncertainty in the ORNL Kintek-491 M-B-based process for calibration of the MDA 7100.

The gas concentration read by the 7100 is determined by the response of its photodetector to the light reflected to it from the spot produced on the chemcassette when it reacts with the gas mixture containing the hydrazine. Therefore, the location and alignment of the photodetector and the illumination lamp with respect to the chemcassette must be carefully maintained to ensure repeatability of this response. The intensity of the illumination lamp must also be carefully maintained within specified limits.

As in the case of section 3.3.2, the concentration printed by the 7100 is calculated by the equations shown below:

$$
X_{h}=\frac{K N}{Q\left(A_{s}-A_{z}\right)} R_{h}+Z_{h}
$$

with

$$
Q=\frac{S_{s}-S_{z}}{A_{s}-A_{z}}
$$

and 


$$
K=\frac{X_{\text {href }}}{X_{h}}
$$

where:

$\mathrm{X}_{\mathrm{h}}$ is the hydrazine concentration reading of the $7100 \mathrm{in} \mathrm{ppb}$

$\mathrm{R}_{\mathrm{h}}$ is the hydrazine concentration range of the $7100 \mathrm{in} \mathrm{ppb}$

$Z_{h}$ is the lowest detectable hydrazine concentration of the $7100 \mathrm{in} \mathrm{ppb}$

$\mathrm{Q}$ is the stain card calibration factor for the stain card optics calibration of the 7100

$\mathrm{N}$ is the photodetector output in counts

$\mathrm{A}_{\mathrm{s}}$ is the actual stain card span color chip reading at the time of the stain card optics calibration

$\mathrm{A}_{\mathrm{z}}$ is the actual stain card zero color chip reading at the time of the stain card optics calibration

$\mathrm{S}_{\mathrm{s}}$ is the stain card span color chip reading at the time of the stain card optics calibration stored in firmware

$\mathrm{S}_{\mathrm{z}}$ is the stain card zero color chip reading at the time of the stain card optics calibration stored in firmware

$\mathrm{X}_{\text {href }}$ is the hydrazine concentration of the reference gas used to calibrate the 7100

$\mathrm{K}$ is the calibration factor obtained by comparing the reference gas 7100 concentration reading to the concentration generated by the $491 \mathrm{M}-\mathrm{B}$

In the ZA calibration method, $\mathrm{X}_{\text {href }}$ is based on the NIOSH 3503 wet test method. The ORNL method uses the $491 \mathrm{M}-\mathrm{B}$ permeation tube system to generate the reference gas. The calculated hydrazine concentration of the reference gas generated by the $491 \mathrm{M}-\mathrm{B}$ system is given by the equations:

$$
X_{\text {halc }}=\frac{E^{*} K_{0}}{F_{T}}
$$

and

$$
K_{0}=\frac{22.4}{M} .
$$

and

$$
X_{\text {href }}=C_{c}{ }^{*} X_{\text {hcalc }}
$$

where:

$\mathrm{X}_{\text {hcalc }}$ is the calculated hydrazine concentration of the $491 \mathrm{M}-\mathrm{B}$ system

$X_{h r e f}$ is the hydrazine concentration of the reference gas used to calibrate the 7100 . Note that $X_{\text {href }}$ is measured by the coulometric titration system.

$\mathrm{C}_{\mathrm{c}}$ is the Kintek $491 \mathrm{M}-\mathrm{B}$ system calibration factor determined by coulometric titration of impinger samples

$\mathrm{E}$ is the emission rate of component compound (hydrazine) from the permeation tube in $\mathrm{ng} / \mathrm{min}$ $\mathrm{K}_{0}$ is the conversion factor which converts the emission rate from weight basis to volume basis $\mathrm{F}_{\mathrm{T}}$ is the total reference gas mixture flow rate in liters/min at standard temperature and pressure (STP) $\mathrm{M}$ is the molecular weight of the component compound (hydrazine)

Combining these equations to determine the uncertainty of $\mathrm{X}_{\mathrm{h}}$ results in:

$$
X_{h}^{2}=\frac{X_{\text {href }} N}{Q\left(A_{s}-A_{z}\right)} R_{h}+Z_{h} X_{h} \text {. }
$$


Assuming $Z_{h} X_{h}$ is negligible

$$
X_{h}=\sqrt{\frac{X_{\text {href }} N}{Q\left(A_{s}-A_{z}\right)} R_{h}}
$$

To determine the uncertainties let

$$
W=\frac{X_{\text {href }} N}{Q\left(A_{s}-A_{z}\right)} R_{h}
$$

and then using the $491 \mathrm{M}-\mathrm{B}$ calibration equation for $\mathrm{X}_{\mathrm{href}}$

$$
W=\frac{C_{c}(22.4 E) N}{\left(M F_{T}\right) Q\left(A_{S}-A_{z}\right)} R_{h}
$$

then

$$
X_{h}=\sqrt{W}
$$

such that

$$
\boldsymbol{u}_{w}=\sqrt{\boldsymbol{u}_{C_{c}}^{2}+\left(\boldsymbol{u}_{N}^{2}+\boldsymbol{u}_{Q}^{2}+\boldsymbol{u}_{A_{S}}^{2}+\boldsymbol{u}_{A_{z}}^{2}+\boldsymbol{u}_{R_{h}}^{2}\right)+\left(\boldsymbol{u}_{E}^{2}+\boldsymbol{u}_{F_{T}}^{2}+\boldsymbol{u}_{M}^{2}\right)}
$$

and

$$
u_{X_{h}}=\frac{1}{2} u_{W}
$$

The uncertainty analysis given here is based on the method described by NIST at http://physics.nist.gov/cuu/Uncertainty/combination.html and assuming normal distributions and no correlation between input estimates and input quantities.

The uncertainty in $\mathrm{N}$ is $10 \%$ which is the combination of the $10 \%$ uncertainty in the optical density of the color spot produced on the chemcassette and uncertainty in the optics system which measures the optical density of the spot. The uncertainty of the optics block system is negligible compared to the uncertainty in the optical density of the color spot produced on the chemcassette.

The uncertainties in the coulometric titration calibrated $491 \mathrm{M}-\mathrm{B}$ system are in $\mathrm{E}, \mathrm{F}_{\mathrm{T}}$, and $\mathrm{M}$ and $\mathrm{C}_{\mathrm{c}}$. The uncertainty in $\mathrm{F}_{\mathrm{T}}$ is $2 \%$ at 0.5 liters/minute and decreases to $0.4 \%$ at 5 liters/minute; the uncertainty in $\mathrm{E}$ is $7 \%$; and the uncertainty in $\mathrm{M}$ is negligible. The uncertainty in $\mathrm{C}_{\mathrm{c}}$ is a combination of the uncertainty in the volume sampled by the impinger sampling system and the uncertainty in the mass of hydrazine in the sampled volume determined by the coulometric titration. The volume sampled is $V=F_{s} t$ with $F_{s}$ being the 
flow rate of the sampling pump and $t$ being the total time the gas mixture was pumped through the impinger. The mass of hydrazine in the impinger sample is determined by coulometric titration of the sample. The uncertainty in the flow rate of the sampling pump is $5 \%$ and the uncertainty in the time is negligible. The uncertainty in the coulometric titration of a typical mass of two micrograms is $5 \%$. Thus the overall uncertainty in $\mathrm{C}_{\mathrm{c}}$ is $7 \%$.

The 7100 related uncertainties in $\mathrm{Q}, \mathrm{R}_{\mathrm{h}}, \mathrm{Z}_{\mathrm{h}}, \mathrm{A}_{\mathrm{s}}$, and $\mathrm{A}_{\mathrm{z}}$ are all less than $1 \%$ and are negligible compared to the $10 \%$ uncertainty in $\mathrm{N}$ thus making a negligible contribution to the uncertainty in $\mathrm{X}_{\mathrm{h}}$

Therefore, using the ORNL method, the largest combined uncertainty for $\mathrm{X}_{\mathrm{h}}$ (the 7100's measurement of hydrazine concentration) is $7.1 \%$.

The uncertainty in $\mathrm{N}$ is $10 \%$ as a result of the combined uncertainty of the uncertainty in the optics system and the uncertainty of the optical density produced by the hydrazine on the chemcassette. Therefore, the smallest possible uncertainty of the 7100 is 5\%. Calibrating the 7100 using the ORNL calibration procedure produces an uncertainty of $7.1 \%$.

This uncertainty applies only to a 7100 that has been calibrated using ORNL's calibration procedure with the $491 \mathrm{M}-\mathrm{B}$ to generate the reference gas and ZA's CAL008 procedure to ensure that the 7100 is being operated correctly and is itself operating according to its specifications so that the uncertainties treated as negligible are in fact negligible.

\subsection{Hydrazine Monitor Calibration Procedure}

The calibration procedure for the ORNL setup described in the previous sections is presented here in a format similar to a USAF Technical Order (T.O.).

\subsubsection{Safety Requirements}

Everyone performing these calibrations must study the Chemical Hygiene Plan and the USAF Hydrazine Safety Video.

(a) Electrical

WARNING

Unless otherwise designated, and prior to beginning the Calibration Process, ensure that all test equipment voltage and/or current outputs are set to zero (0) or turned off, where applicable. Ensure that all equipment switches are set to the proper position before making connections or applying power.

(b)Pressure

WARNING

Each technician assembling high or low pressure lines for test purposes must be familiar with all applicable directives and safety precautions contained in applicable OSHA Standards, and T.O. 00-25223. It is recommended that a protective shield be used during the pressurization of all Test Instruments (TI) not designated explosion safe, as identified IAW T.O. 33-1-19 Section 4-67, up to and including 500 psi and mandatory for non-explosion safe gauges over 500 psi. 
WARNING

Hydrazine is highly toxic. This procedure should be performed inside of a bench top Fume Hood which has been vented to the outside of the laboratory. Always keep Hydrazine Permeation Tubes in plastic containers with desiccant when not in use. Store container in a cool $\left(25^{\circ} \mathrm{C}\right.$ or lower $)$ location.

(d) Hydrazine Permeation Tube Safety Checklist

WARNING

HYDRAZINE IS HIGHLY TOXIC. See the hydrazine MSDS at https://fscimage.fishersci.com/msds/11040.htm. Hydrazine, in all its forms, is extremely hazardous to unprotected personnel. It can be absorbed into the body through the skin, by inhalation, and by ingestion. Regardless of how it enters the body, even trace amounts of hydrazine can have serious health and environmental impacts. Just a few drops of hydrazine on the skin can be fatal. This procedure should be performed inside of a bench top Fume Hood that has been vented to the outside of the laboratory. Always keep Hydrazine Permeation Tubes in plastic containers with desiccant when not in use and when being transferred between locations. Store the container in a cool $\left(25^{\circ} \mathrm{C}\right.$ or lower) fume hood vented to outside the laboratory.

Hydrazine used in this calibration procedure is sealed inside Teflon permeation tubes, which are heated to produce vapor streams. The safety checklist for the calibration process centers on a few simple rules for handling the tubes of hydrazine. Alert all personnel using the lab where hydrazine permeation tubes are being stored and when the permeation tubes are in use or being transferred to or from their storage location. Post signs and use floor markings to indicate the part of the lab that should be entered only by authorized personnel (people with required hydrazine safety training).

\section{Checklist}

d.1 Do not let hydrazine touch your skin.

d.2 Always wear hydrazine impermeable gloves. And even though wearing gloves, do not directly handle the hydrazine tubes with your gloved hands.

d.3Always wear a fully buttoned hydrazine impermeable lab coat while handling the hydrazine permeation tubes.

d.4When donning gloves, tuck the distal end up under the lab coat. Keeping the gloves inside sleeves will reduce the risk of contamination. If splashing is possible seal the gloves to the sleeves of the lab coat with hydrazine impervious sealing tape.

d.5 If hydrazine has gotten on the gloves, wash the gloves before removing them. Remove your gloves and lab coat so as not to come in contact with any outside surfaces. This will minimize cross contamination. Having removed gloves and lab coat, wash hands and arms thoroughly.

d.6Make sure that the shower and eyewash stations are available and work properly and that they are routinely maintained and serviced on schedule. They should be fully functional and available within 10 seconds in case of emergency.

d.7 Do not let hydrazine near your mouth.

d.8 Do not eat or drink anything or put anything into your mouth while working with the hydrazine permeation tubes or while working in the area where the tubes are being used.

d.9Do not let hydrazine get into your eyes.

d.10 Always wear safety glasses with side shields. Permeation tubes contain small quantities of the liquid hydrazine in sealed tubes and splashing is not possible unless the tubes seals are broken. 
If splashing of the hydrazine becomes possible, then chemical goggles and a full face shield are required.

d.11 Do not remove your safety glasses or put anything in your eyes (such as rubbing your eyes under your safety glasses) while working with the permeation tubes or while working in the area where the tubes are being used.

d.12 Perform all work with the hydrazine permeation tubes inside a fume hood that has been setup so it is operating at a face velocity of $100 \mathrm{ft} / \mathrm{min}$ and is regularly checked to see that it is operating correctly. The doors of the hood should be set up in the proper operating position. This will ensure correct airflow velocities. It is important that the air flows INTO the hood, and at the proper flow rate. Check temperatures inside and outside of hood to make sure they are between 19 and $26 \mathrm{C}$. This is the desirable range of environmental temperatures for optimum operation of the calibration equipment and test instruments.

d.13 Store the hydrazine tubes which are not in use in closed containers in a different well-ventilated fume hood close to the fume hood where they are to be used.

d.14 Do not have any other chemicals close by or in either the working fume hood or the storage fume hood. They could affect the monitoring of hydrazine.

d.15 Never breathe the vapor.

d.16 Do not place your head inside a fume hood in which hydrazine permeation tubes are being used or stored.

d.17 Do not remove the permeation tubes from their storage containers when transferring them from their storage area to the fume hood where they will be used.

d.18 When dealing with hydrazine permeation tubes under normal operating conditions, the minimum protective equipment required would include safety glasses with side shields, hydrazine impermeable gloves, and a properly fitting hydrazine impermeable lab coat. The coat and gloves should be free of tears, rips or holes and the coat should have a complete set of buttons, all of which should be fastened in order to provide maximum protection.

d.19 An area hydrazine monitor should be used in the laboratory if it is used for hydrazine permeation tube work on a frequent basis or for long periods of time.

d.20 Personal hydrazine dosimeters should be used by personnel while using the hydrazine permeation tubes if they use the tubes frequently or for long periods of time.

d.21 If a fume hood or the laboratory HVAC system fails while the hydrazine permeation tube system is in use, notify designated personnel, shut down the hydrazine permeation tube system, close the hood doors, and evacuate the laboratory and lock the laboratory doors.

d.22 Do not enter the laboratory until the fume hoods and HVAC system are again operational and have lowered the concentration of hydrazine in the laboratory below the exposure limit values as measured by trained personnel in protective clothes and equipment and using a calibrated hydrazine detector.

d.23 Do not put your head inside a fume hood containing hydrazine permeation tubes if the hood has failed or is not running properly.

d.24 Following the procedure in the checklist above will make a hazardous exposure to hydrazine unlikely, however, incorrect handling of permeation tubes can cause a puncture in the end or in the side of the tube or overheating can cause a tube to burst.

d.25 Never handle hydrazine permeation tubes with sharp objects.

d.26 Always keep the operating temperature of the hydrazine permeation tube below its safe operating temperature of $77 \mathrm{C}$.

d.27 In case of an accident, close the fume hood doors, alert emergency personnel, evacuate the area and lock the lab doors.

d.28 If anyone has skin contact with leaking liquid hydrazine, rescuers in proper personal protective equipment immediately move the victim from the contaminated area, remove victim's contaminated clothing and treat as hazardous waste, flush affected area(s) with water for 15-20 minutes, seek medical attention, and report all exposures to supervision. 
d.29 If anyone has eye contact with leaking liquid hydrazine, rescuers in proper personal protective equipment immediately move the victim from the contaminated area, flush eyes with large amounts of water for 15-20 minutes occasionally lifting upper and lower eyelids, seek medical attention, and report all exposures to supervision.

d.30 If anyone has ingested hydrazine, rescuers in proper personal protective equipment immediately move the victim from the contaminated area, have victim drink large amounts of water, do not use milk, do not use ipecac to induce vomiting, seek medical attention, and report all exposures to supervision.

d.31 If anyone has inhaled hydrazine above the OSHA personal exposure level concentration of $1 \mathrm{ppm}$, rescuers in proper personal protective equipment immediately move the victim to fresh air, if the victim is not breathing, perform artificial respiration, seek medical attention, and report all exposures to supervision.

d.32 In order to go back into the laboratory and clean up, devise a plan for re-entering the area using adequate protective clothing... respirators, masks, aprons, gloves, boots etc. Be sure the clothing is appropriate for the situation and inspect it to ensure that it is not torn. It should fit properly and should be donned in the prescribed manner.

d.33 If the hydrazine contamination is confined within an operating hood, don hydrazine impermeable lab coat, apron, gloves sealed to the lab coat, and shoe covers as well as chemical goggles and a full face shield and then go in and do the clean up. The additional protection is needed because splashing is possible if the liquid hydrazine has leaked out of the permeation tube.

\subsubsection{Calibration Overview}

\section{(a) Equipment}

(a.1) Test Instrument (TI) Description

\begin{tabular}{|l|l|l|l|}
\hline $\begin{array}{l}\text { Test Instrument (TI) } \\
\text { Characteristics }\end{array}$ & Performance Specifications & Test Method & Comments \\
\hline & & & \\
\hline Detector (Hydrazine & Range: 0 to $2000 \mathrm{ppb}$ & Compared to a & \\
Gas) & Hecuracy: $\pm 10 \%$ & Generazine & \\
ZA 7100 & Accor System & \\
\hline
\end{tabular}

(a.2) Reference Gas Generation System Description

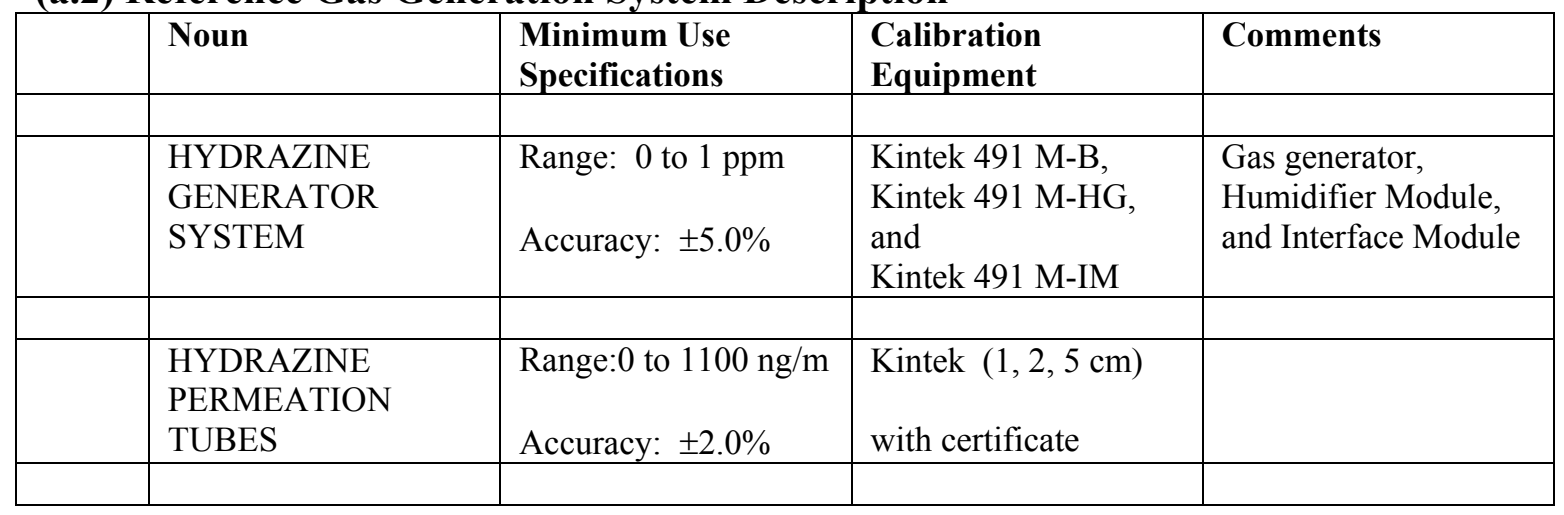


(a.3) Accessory Instruments and Supplies

\begin{tabular}{|l|l|l|l|l|}
\hline & Noun & $\begin{array}{l}\text { Minimum Use } \\
\text { Specifications }\end{array}$ & $\begin{array}{l}\text { Calibration } \\
\text { Equipment }\end{array}$ & Comments \\
\hline & Barometer & $\begin{array}{l}\text { Range: } 28.00 \text { to } 31.00 \\
\text { in of Hg } \\
\text { Accuracy: } \pm 1.0 \%\end{array}$ & $\begin{array}{l}\text { Wallace \& Tiernan } \\
\text { Model FA 139200 }\end{array}$ & \\
\hline & & & & \\
\hline & $\begin{array}{l}\text { PRESSURE } \\
\text { SOURCE }\end{array}$ & $\begin{array}{l}\text { Range: } 0 \text { to } 70 \text { psig } \\
\text { Accuracy: N/A }\end{array}$ & $\begin{array}{l}\text { Nitrogen Local } \\
\text { Purchase }\end{array}$ & \\
\hline & & & & \\
\hline & PRESSURE & $\begin{array}{l}\text { Range: } 0 \text { to } 70 \text { psig } \\
\text { Accuracy: N/A }\end{array}$ & Victor & \\
\hline & REGULATOR & $\begin{array}{l}\text { Range: N/A } \\
\text { Accuracy: N/A }\end{array}$ & Locally furnished & \\
\hline & FUME HOOD & $\begin{array}{l}\text { Range: } 32.0 \text { to } 140.0 \\
\text { Accuracy } \pm 0.1 \mathrm{~F}\end{array}$ & $\begin{array}{l}\text { VWR } \\
\text { Model 33519-043 }\end{array}$ & \\
\hline & Thermometer & $\begin{array}{l}\text { Range } 10.0 \text { to } 95.0 \\
\text { Accuracy } \pm 1.5 \%\end{array}$ & $\begin{array}{l}\text { VWR } \\
\text { Model 33519-043 }\end{array}$ & \\
\hline & Hygrometer & &
\end{tabular}

\subsubsection{Calibration Method}

\section{(a) Fume Hood Setup}

Since the calibration equipment and TI must be used in a fume hood, the first step of the calibration procedure is to be sure that the fume hood is turned on and that the fume hood is operating with a face velocity of $100 \mathrm{ft} / \mathrm{min}$ into the hood. Use a calibrated air velocity instrument to measure the face velocity of the hood at several points to be sure that the hood is operating correctly. After the calibration equipment and TI have been placed in the hood measure the face velocity again to see that the calibration setup is not blocking the hood's airflow. The temperature, pressure and relative humidity inside the hood should be monitored and recorded to determine if they are varying more than the calibration conditions allow and to be used for to correct for any environmentally caused effects.

\section{(b) Humidified Reference Gas Generation System Setup}

The Kintek 491M Reference Gas Generation System is composed of the 491M-B gas mixing permeation module, the 491M-HG humidification module, and the 491M-IM interface module. These modules must be interconnected with tubing to ensure the correct operation of the system.

Figure 3.4 shows a simplified flow diagram and interconnections of the 491M-B and 491M-HG modules. The flow diagram illustrates what is happening internally in each of the interconnected units. For a more detailed description and functions of various controls, please refer to the respective user manuals (references 1 and 2).

Dilution gas enters the 491M-B and is immediately pressure-regulated to $50 \mathrm{psig}$. The flow then splits into two parts. One part (called the metered flow) goes to the system flow meter. It is used as the main carrier and main dilution flow in the Span mode. The remaining part of the flow is the "unmetered flow." 


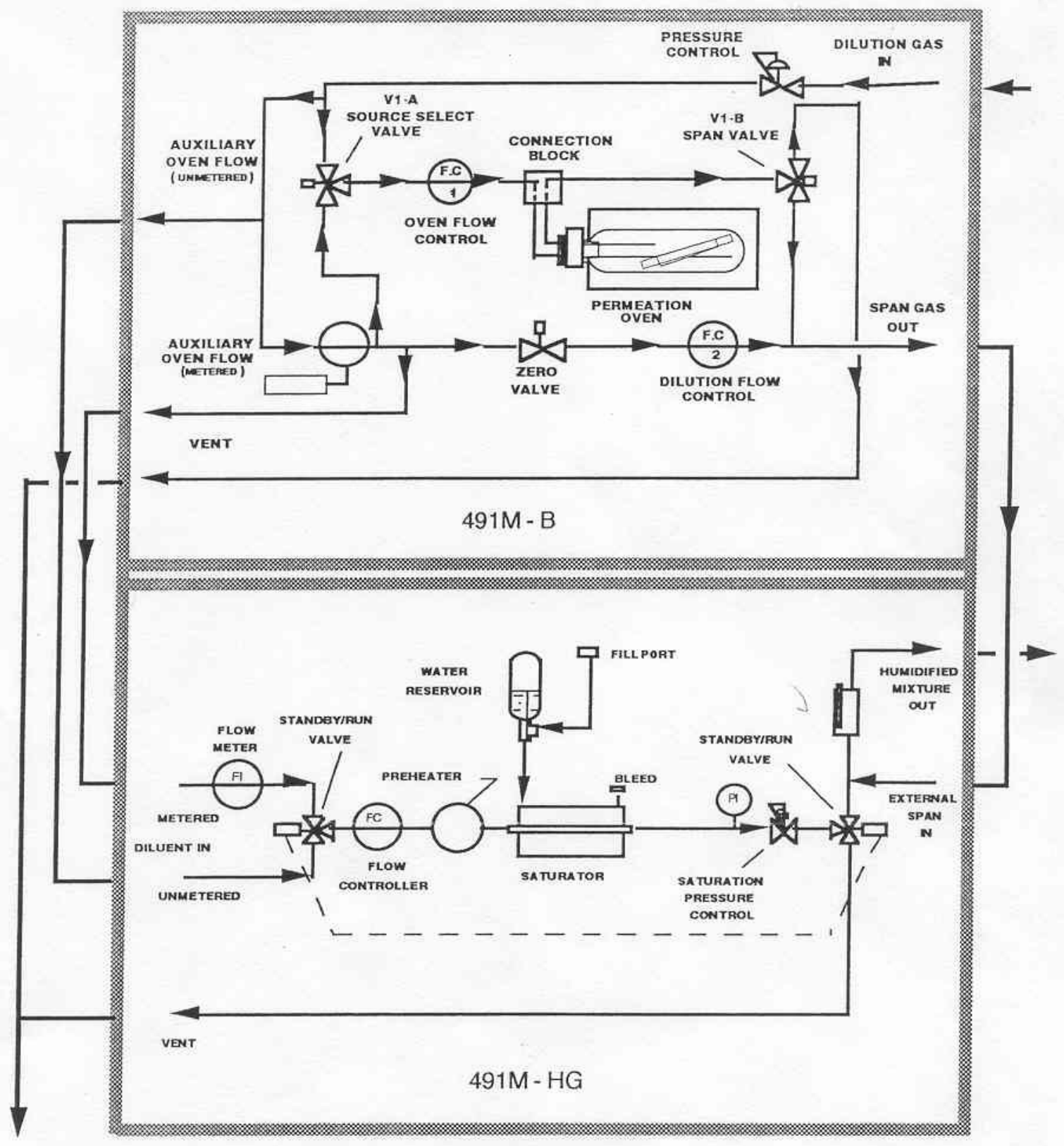

Fig 3.4 Simplified flow diagram and interconnections of the 491M-B and 491M-HG modules. 
It is used to maintain equilibration of the permeation ovens and 491M-HG in the ZERO and STANDBY modes. These outputs are connected to the A and B ports on the rear panel of the 491M-B. The "metered flow" (port A) supplies carrier gas to the permeation ovens, main dilution flow and metered gas to accessory modules. The 491M-HG uses either the metered flow (in the RUN mode) or unmetered flow (in the STANDBY mode) from the 491M-B as "humidifier flow." Gas entering from either port passes through the humidifier flow controller, preheater, and saturator, where it becomes saturated with water vapor. In the RUN mode, the humidified gas flow is indicated on the front panel meter of the 491M-HG. In the STANDBNY mode, the flow remains the same as in the RUN mode, but it is not indicated on the flow meter.

Dry Zero or Span Gas (Zero plus Carrier and Permeate) flows from the 491M-B and enters the 491M-HG through the port marked "EXTERNAL SPAN IN," where it mixes with the water saturated humidifier flow. The final humidifier mixer then passes over an RH sensor and leaves the system from the "HUMIDIFIED MIXTURE OUT" port.

The total dilution flow is indicated on the front panel of the 491M-B. To adjust the humidity level, the Zero flow in both the 491M-B and humidifier are independently adjusted, but the total flow is always indicated on the $491 \mathrm{M}-\mathrm{B}$.

\section{NOTE: It is extremely important that tubing interconnections, especially the $A$ and $B$ ports at the rear of the rear of the system, be free of leaks. A leak in this flow path causes a mixture concentration error.}

The $491 \mathrm{M}-\mathrm{HG}$ is always the last active module in a $491 \mathrm{M}$ system. (Note that the interface module is not an active module in this sense.) This insures that humidity is added to the mixture just prior to use. A $491 \mathrm{M}-\mathrm{IM}$ interface module is used to control distribution of the mixture.

The front panel connections of the modules are made as follows:

The Diluent gas is connected to the $491 \mathrm{M}-\mathrm{B}$ at the Diluent port. The permeation tube that is placed inside the permeation bottle in the $491 \mathrm{M}-\mathrm{B}$ 's permeation oven supplies the trace gas. The $491 \mathrm{M}-\mathrm{B}$ combines the diluent and trace gas flows and they are sent to the Span Gas port. The Span Gas port on the $491 \mathrm{M}-\mathrm{B}$ is connected to the External Span In port of the $491 \mathrm{M}-\mathrm{HG}$. The $491 \mathrm{M}-\mathrm{HG}$ adds the needed water vapor to produce the desired humidity by combining the mixture of diluent and trace gas flowing in through its External Span In port with a humidified portion of the diluent flow coming from the $491 \mathrm{M}-\mathrm{B}$ back panel to $491 \mathrm{M}-\mathrm{HG}$ back panel connection described above. This forms the humidified mixture which is sent to the Humidified Mixture Out port of the $491 \mathrm{M}-\mathrm{HG}$. The Humidified Mixture Out port of the $491 \mathrm{M}-\mathrm{HG}$ is connected to the Mixture In port of the $491 \mathrm{M}-\mathrm{IM}$. The test instrument sampling system is then connected to either the Output A, Output B, or Syringe ports of the 491 M-IM.

\section{(c) Kintek 491 M-B Gas Generator Start-Up Instructions}

c.1 After careful inspection of the instrument and its accessories, the $491 \mathrm{MB}$ is ready for the first testrun.

c.2 The 491M-B comes with an easy-to-remove cabinet cover. Remove cabinet cover to gain access to the internal fixtures of the instrument.

C.3 Plug one end of the power cord into the rear panel of the $491 \mathrm{M}-\mathrm{B}$ module. Plug the other end into an outlet or power strip. Refer to Figure 2 in the 491 M-B manual for details. 
c.4 Cap off the span gas out port (on front panel ) with the 1/4" grooved plug; cap off the vent port ( on rear panel ) with the $1 / 8$ " cap ( part number SS 200 - P).

c.5 Turn the system switch to STBY (refer to the appendix in the $491 \mathrm{M}-\mathrm{B}$ manual for explanation on the system switch positions).

c.6 Connect oven bypass jumper to the "oven connection block". Refer to the appendix in the 491 M-B manual for more details.

c.7 Turn the power switch on. Set the temperature to $30{ }^{\circ} \mathrm{C}$, making sure that the +100 switch is not depressed. Depressing this switch will increase the set temperature by $100{ }^{\circ} \mathrm{C}$.

C.8 Press the flow switch on the front panel. Display panel reading will gradually reach 0.00 . (Note: if this fails to occur in $30 \mathrm{~min}$, the flowmeter needs zero adjustment. This is done by locating the flow meter inside the internal fixtures of the $491 \mathrm{mb}$. The zero adjust knob is located on the side of the flowmeter. Adjust the knob till 0.00 is attained. See figure 3 and 4 in the $491 \mathrm{M}-\mathrm{B}$ manual for flowmeter location.)

c.9. Connect the dilution gas into the diluent in port (on front panel) at a pressure between 60-100 psig from source

c.10 Turn dilution adjust knob clockwise all the way. The flow controller is now fully open.

c.11 Turn system switch to span. Display panel should gradually run to 0.00. (Note: if this fails to occur, see leak check under trouble shooting on page 19 in the 491 M-B manual.)

c.12 Press the temp button (on the front panel) to display the temperature. It should read $30.0^{\circ} \mathrm{C}$. The temperature might take $15-30 \mathrm{~min}$ to stabilize. Once at $30.0 \mathrm{c}$ the heater indicator will cycle.

c.13 Turn dilution adjust knob counter-clockwise all the way. This will stop the pressure build up in the system and the grooved plug may now be taken out of the span gas out. Slowly loosen the nut to release the internal pressure. (Safety Caution: if the pressure is not drained slowly, the grooved plug may shoot out at high speed.)

c.14 Press the flow button to observe flow on the display panel. It should read approximately $0.10 \mathrm{l} / \mathrm{min}$. If it doesn't read $0.10 \mathrm{l} / \mathrm{min}$, adjust the oven flow adjust till it reads $0.10 \mathrm{l} / \mathrm{min}$.

c.15 Remove the oven bypass jumper

c.16 Remove the vent cap.

SAFETY: Before operating the system the vent caps must be removed to avoid potentially dangerous and/or damaging pressure buildup in the system.

C.17 Once the test-run is complete, the $491 \mathrm{MB}$ is now ready for humidification module setup.

\section{(d) Humidification Module - 491 M-HG Start-Up}

d.1 Before start-up be sure of the following:

(1) that there is water in the reservoir,

(2) that the pressure adjust knob is fully counterclockwise,

(3) that the system is connected to the auxiliary dilution flow outputs (A and B ports) of a $491 \mathrm{MB}$ Base Module (either directly or through serially connected accessory modules), or an 491 $M-S D$ Secondary Dilution Module, and

(4) that the humidifier module vent cap is removed.

d.2 Set the Run/Standby switch in the STANDBY position. Open the flow control approximately 5 turns. Turn on the power to the unit using the On/Off switch. Allow the system to warm up and flush for at least 30 minutes.

d.3 Set the zero flow indicated on the $491 \mathrm{M}-\mathrm{B}$ to 0.5 liters/minute. 
d.4 Set the Meter Function Switch to the PRESSURE position. The reading should be zero, or, at least below 5 psig. If there is a substantially elevated pressure, lower it by rotating the Pressure Control knob counterclockwise.

d.5 Set the Meter Function Switch to the RELATIVE HUMIDITY position. Allow the unit to warm up for about 2 hours, or at least until the indicated RH is below $10 \%$.

d.6 Check for proper operation as follows. Set the Run/Standby Switch in the $\boldsymbol{R} \boldsymbol{U} \boldsymbol{N}$ position. Move the Meter Function Switch to the FLOW position. Using the Flow Adjust Knob, set the flow to approximately 0.5 liters/minute. Move the Meter Function switch to the RELATIVE HUMIDITY position. The meter should indicate 40 to $60 \%$ relative humidity.

d.7 Using the Flow Adjust Knob, vary the flow through the $491 \mathrm{M}-\mathrm{HG}$ and observe the changes in relative humidity. Clockwise rotation of the knob should increase $\mathrm{RH}$, counterclockwise rotation should decrease RH.

d.8 Set the Meter Function Switch to the PRESSURE position. Raise the Saturation Pressure to about 15 psig using the Pressure Adjust knob. Set the Meter Function switch back to the RELATIVE

HUMIDITY position. There should be an immediate change in the \% $\mathrm{RH}$ reading. Check to be sure that changing Saturation Pressure changes \%RH.

d.9 Set the Meter Function Switch to the OUTPUT TEMPERATURE position. The temperature should be between $22^{\circ}$ and $30^{\circ} \mathrm{C}$. This is the temperature at which the indicated relative humidity is measured. A correction factor table will be used to correct the indicated value to the value at ambient conditions.

d.10 Successful completion of steps 1- 9 above indicates that the system is setup and functioning correctly.

(e) Test Atmosphere Interface Module 491M-IM

Before use be sure that the mode select switch is set to atm. and that the interface module vent cap is removed.

\section{(f) Calibration Procedure Description}

The gas detector calibration system is composed of a Kintek 491 reference gas generation system, the test instrument (TI), and ambient temperature, pressure, and humidity sensors. The Kintek 491 reference gas generation system includes a Kintek 491 M-B gas mixer connected to the Kintek 491 HG humidifier and the Kintek 491 IM gas sampling interface. The generator system produces a reference gas with the desired gas concentration and humidity to be used in calibrating gas detectors.

The system is being used to calibrate hydrazine detectors. The system creates the desired reference concentration by combining a dry nitrogen diluent gas flow with a permeation tube generated hydrazine flow and then adding a humidified nitrogen flow. The flow rates of the diluent nitrogen and the humidified nitrogen are adjusted to produce a reference gas with the desired humidity and hydrazine concentration. This reference gas fills and flows through the interface module that can then be sampled by the TI and with the impinger sample collection system.

The Kintek 491 reference gas generation system is calibrated using coulometric titration to determine the hydrazine concentration of the sample atmosphere in the interface module. The sample atmosphere is sampled by pumping a measured flow of the reference gas into an impinger for a measured time interval at the measured temperature and pressure. The amount of hydrazine in each of these impinger samples is then determined using a coulometric titration procedure. The concentration of hydrazine in the reference gas sample atmosphere is then determined from the volume of gas that was pumped through an impinger to collect the hydrazine and the amount of hydrazine in the impinger. 
Using the results of the concentrations determined by the coulometric titration a calibration equation is created for the Kintek 491 reference gas generation system. This calibration equation is then used to determine the concentration of the reference gas in the sample atmosphere of the interface module. The test instrument is then connected to the sample atmosphere and calibrated based on the sample atmosphere's known concentration as determined by the Kintek 491 reference gas generation system's calibration equation. Therefore, it is only necessary to collect impinger samples each time the Kintek 491 reference gas generation system is calibrated.

Starting with the largest concentration sample atmosphere, the sample atmosphere is separately connected to the sample port of the TI and it is used to measure the hydrazine concentration of the sample atmosphere. If these measurements are within plus or minus $5 \%$ of the reference gas concentration generated by the Kintek gas generation system then the concentration of the sample atmosphere is lowered and the process above is repeated. When the concentration of the sample atmosphere is lowered again, if the TI does not read within plus or minus $5 \%$ reference gas concentration it is rejected as no longer able to be calibrated without repair. If the TI is still within the plus or minus $5 \%$ of the reference gas concentration, this process may be repeated for one more lower concentration if needed. When three different reference concentrations have been completed successfully they are use to produce the calibration certificate for the TI.

\section{(g) Calibration Procedure Steps}

g.1 Assemble the Gas Generation System inside the fume hood as described above.

g.2 Check to see that the fume hood is operating correctly.

g.3 Connect the diluent source to the 491 M-B Diluent port.

g.4 Perform Startup procedures for the modules as described above.

g.5 Set the zero flow of the diluent in the $491 \mathrm{M}-\mathrm{B}$ to $0.5 \mathrm{slpm}$.

g.6 Install the permeation tube into the permeation tube bottle of the $491 \mathrm{M}-\mathrm{B}$ as described below.

g.7 Set the 491 M-B's permeation oven temperature controller to the temperature required to produce the permeation tube's calibrated permeation rate.

g.8 Set the humidification module (491 M-HG) to produce the desired humidity of the humidified gas mixture by adjusting both the diluent zero flow with the $491 \mathrm{M}-\mathrm{B}$ and the humidified diluent flow with the $491 \mathrm{M}-\mathrm{HG}$.

g.9 If the Gas Generation System has not been calibrated or is out of calibration, perform the coulometric titration calibration of the Gas Generation System as described below.

g.10 Calculate the total combined flow of the humidified reference gas mixture needed to generate the highest desired reference gas concentration at the desired humidity. Use the gas generation system's coulometric titration calibration equation to determine the needed Kintek 491 M-B's output concentration to provide the required humidified reference gas mixture concentration.

g.11 Set the total flow by adjusting both the $491 \mathrm{M}-\mathrm{B}$ dilution adjust and the $491 \mathrm{M}-\mathrm{HG}$ flow adjust knobs until the $491 \mathrm{M}$-B flow indicator shows the total flow calculated in step (11) while maintaining the desired humidity of the humidified mixture.

g.12 When hydrazine is the trace gas mixture being generated it is necessary to let the system run at these settings at least 12 to 15 hours to condition the modules and connecting tubing and achieve initial equilibrium. After this initial equilibration period, each new lower concentration only requires about 1 to 2 hours to reach equilibrium.

g.13 Connect the Test Instrument (TI) to the 491 M-IM Output A or Output B port.

g.14 If the TI is a ZA 7100 and a humidity effect characterization is not available, perform the humidity effect characterization procedure described below.

g.15 Either set up the TI to periodically sample the system during the initial equilibration period or be sure to condition the TI's sampling tubing for at least 30 minutes before collecting data. 
g.16 After conditioning has been completed and equilibrium is established take several consecutive measurements with the TI and average them. Compare this average reading of the TI to the reference gas concentration and determine if more measurements are needed or if the TI must be adjusted. Record the TI readings; the $491 \mathrm{M}-\mathrm{B}$ gas generator total flow reading; the relative humidity, temperature and humidifier flow readings from the $491 \mathrm{M}-\mathrm{HG}$; the temperature, relative humidity and pressure in the fume hood, and the date and time.

g.17 Lower the reference gas concentration to the next desired concentration by repeating steps (10) and (11).

g.18 Repeat Step (16)

g.19 Repeat Steps (16) and (17) for as many times as required.

g.20 Enter the recorded data into a spreadsheet and analyze the data to produce the calibration certificate and graphs.

\section{(h) Installation of Permeation Tube(s)}

Each permeation source is treated differently when it comes to installing it into the $491 \mathrm{M}-\mathrm{B}$. The following section describes a method for installing disposable permeation tubes. Refer to individual manual for details on other types of permeation sources. Additional permeation sources are listed on page 25 and 26 of the 491 M-B manual.

Disposable Tubes:

Disposable tubes are installed in the $491 \mathrm{M}-\mathrm{B}$ by using a glass adapter bottle:

h.1 unscrew the aluminum coupler assembly

h.2 Place the disposable permeation tube(s) inside the adapter bottle

h.3 Screw back the aluminum coupler assembly making sure the " 0 " ring is properly placed

h.4 Place the adapter bottle inside the permeation oven

h.5 Connect the Teflon inlet tube (the long tube feeding to the bottom of the bottle) to the inlet port of the Connection Block. The inlet port in the Connection Block is the one nearest the oven (marked with a black dot).

\section{NOTE:}

Hand tighten the connections between the Teflon tube and the connection block to avoid damaging the seal in the block. Refer to Appendix on page 22 of the 491 M-B manual for details.

h.6 Connect the other Teflon tube to the other port in the Connection Block as shown in Fig. 4.2.

\subsubsection{Calibration of the Kintek 491 Gas Generation System Using Coulometric Titration}

The Kintek reference gas generation system itself is periodically calibrated using an ORNL-constructed coulometric titration system to verify the hydrazine concentration of the sample atmosphere in the interface module. The Kintek reference gas is then used to calibrate the hydrazine monitors. Thus, coulometric titration is only used to periodically assess the performance of the Kintek reference gas generation system, and is not required for hydrazine monitor calibrations. The coulometric titration system is described in detail in chapter 4

\section{(a) Interface Module (491 M-IM) Test Atmosphere-Hydrazine $\left(\mathrm{N}_{2} \mathrm{H}_{4}\right)$ Mixture Sampling}

a.1 Connect one end of the BEV-A-LINE IV sample tube to a 
$491 \mathrm{M}-\mathrm{IM}$ Output port and attach an impinger connector to the other end. Fit the connector to the center stem of the impinger. Connect the impinger sidearm to the input of the Accucal rotameter with tubing through a glass trap. Connect the output of the Accucal rotameter to the pump intake.

a.2 Prior to collecting vapor samples, condition the impinger sample lines by passing sample through the tubing for at least 30 minutes. Longer conditioning time may be needed if the vapor concentration to be sampled is 10 to $50 \mathrm{ppb}$.

In order to yield a 4-minute coulometric titration, estimate the required sample volume, absorbing solution volume, and required aliquot for coulometric titration using the following equation:

$$
\mathrm{V}=(\mathrm{S})(1.52)
$$

$(\mathrm{A})(\mathrm{C})$

$\mathrm{V}=$ Required vapor sample volume, liters.

$\mathrm{S}=$ Total volume of diluted impinger sample, $\mathrm{ml}$

$\mathrm{A}=$ Aliquot transferred to the titrator vessel, $\mathrm{ml}$.

$\mathrm{C}=$ Expected sample concentration in ppm.

where

$$
1.52 \mathrm{ppm}-\text { liter }=\frac{1.55 \mathrm{E}-8 \mathrm{moles} / \mathrm{min} \times 4 \mathrm{~min}}{4.08 \mathrm{E}-8 \mathrm{~mole} /(\text { liter-ppm })}
$$

a.3 Adjust the control on the pump until the measured flow is 1.0 standard liters per minutes (sLpm). The flowrate should be verified and recorded.

a.4 Add $15 \mathrm{ml}$ of $0.1 \mathrm{M} \mathrm{H}_{2} \mathrm{SO}_{4}$ into the impinger. Ensure that using a water seal properly seals the impinger

a.5 After the system has equilibrated connect the sample tube to the impinger. Turn on the sampling pump, open the $491 \mathrm{M}-\mathrm{IM}$ output valve connected to the impinger, and start the flow timer as close to simultaneously as possible.

a.6 Record the initial Accucal Rotameter meter reading. Read the rotameter at two or three equal intervals during each sampling period and at the end of the sampling period and record the readings.

a.7 When the desired volume of vapor has been scrubbed, turn off the sampling pump, close the $491 \mathrm{M}$ IM output valve connected to the impinger, and stop the flow timer as close to simultaneously as possible. Disconnect the impinger from the sample tube, and then the pump intake tube. Record the total time for the sample collection and use it with the average pump flow rate measured by the rotameter to determine the actual sample volume $(\mathrm{V})$

a.8 Repeat steps a.1 through a.7 until two or more impinger samples have been collected for this 491 reference gas generation system concentration.

a.9 Using the procedure described in section 4.3 .3 steps g.10 and g.11 change the output concentration of the 491 reference gas generation system and repeat a.1 through a.8. 
a.10 Repeat a.9 until two or more impinger samples have been collected at each of three or more different 491 reference gas generation system concentrations.

\section{(b) Coulometric Titration of Impinger Samples_-Determination of Concentrations of Hydrazine $\left(\mathrm{N}_{2} \mathrm{H}_{4}\right)$ In Nitrogen or Air by the Coulometric Titration Method}

This procedure details the methodology for determining the concentrations of hydrazine $\left(\mathrm{N}_{2} \mathrm{H}_{4}\right)$ in nitrogen or air by coulometric titration of impinger samples. This procedure is applicable from $1 \mathrm{ppb}$ to $100 \mathrm{ppm}$.

\section{b.1 Apparatus}

1) Air sampling pump, Gilian HFS 513

2) Beaker, $50 \mathrm{~mL}$, for a coulometer reaction vessel.

3) Beaker, $500 \mathrm{~mL}$, for $0.1 \mathrm{M}$ sulfuric acid $\left(\mathrm{H}_{2} \mathrm{SO}_{4}\right)$ storage vessel.

4) Coulometer, $0.100 \mathrm{~mA}$, with platinum wire electrodes.

5) EPPENDORF micropipette or equivalent micropipette

6) Ground glass stoppered brown reagent bottles, or FEP black bottles.

7) Impinger, glass straight tube type, $25 \mathrm{ml}$. Other sizes of non-fritted impingers may be used.

8) Magnetic stirrer.

9) Recorder calibrated for chart speed.

10) Scoop to measure approximately $0.4 \mathrm{~g}$ potassium bromide $(\mathrm{KBr})$.

11) Stirring bar and magnetic removal wand.

12) Tubing, assorted lengths. BEV-A-LINE IV recommended for contact with $\mathrm{N}_{2} \mathrm{H}_{4}$.

13) Volumetric flasks, assorted.

14) Volumetric pipettes, assorted.

15) Accucal rotameter, or equivalent, calibrated.

\section{b.2 Chemicals}

1) $\mathrm{KBr}$, reagent grade.

2) $\mathrm{H}_{2} \mathrm{SO}_{4}$, concentrated $98 \%$, reagent grade.

3) Deionized water (DI), resistivity 16 Mega-ohm-cm or higher.

4) Hydrazine sulfate $\left(\mathrm{N}_{2} \mathrm{H}_{4} \cdot \mathrm{H}_{2} \mathrm{SO}_{4}\right)$, anhydrous, reagent grade.

NOTE:

In the remainder of this procedure, parts per million (ppm) and parts per billion (ppb) are referred to on a volume/volume (v/v) basis.

\section{b.3 Procedure}

\section{Preparation of Reagents:}

\section{b.3.1 Preparation of $0.1 \mathrm{M}, \mathrm{H}_{2} \mathrm{SO}_{4}$ :}


Pipette $11.2 \mathrm{ml}$ of concentrated $\mathrm{H}_{2} \mathrm{SO}_{4}$ into a $2000 \mathrm{ml}$ volumetric flask containing approximately $1700 \mathrm{ml}$ of DI water. Add DI water to the mark and mix well. This solution is used as the background liquid for the coulometric titration and for electrode storage and cleaning.

\section{b.3.2 Preparation of Hydrazine stock solution, 1000 ppm.}

Dissolve $0.8120 \mathrm{~g}$ of anhydrous hydrazine sulfate in a small amount of $0.1 \mathrm{M} \mathrm{H}_{2} \mathrm{SO}_{4}$ in a $200 \mathrm{ml}$ volumetric flask. Add $0.1 \mathrm{M} \mathrm{H}_{2} \mathrm{SO}_{4}$ to $200 \mathrm{ml}$ mark. Transfer this solution to a brown glass reagent bottle and store in the fume hood designated for hypergolic fuel. The label on this bottle should contain the following information: description, solution date, and initials of the person who made the solution. A fresh stock solution should be prepared every 6 months.

b.3.3 Prepare a $2.0 \mathrm{ppm}$ working standard solution by using a volumetric pipette to transfer $0.5 \mathrm{ml}$ of hydrazine stock solution into a $250 \mathrm{ml}$ volumetric flask. Fill to the mark with $0.1 \mathrm{M} \mathrm{H}_{2} \mathrm{SO}_{4}$ and then mix well. This working standard should be freshly prepared each month.

\section{Analysis of Samples}

The recommended parameters for the integrator chart recorder are as follows:

$$
\begin{aligned}
& \text { Range }=500 \mathrm{mV} \\
& \text { Chart speed }=2 \mathrm{~cm} / \mathrm{min} \\
& \text { Zero line }=1 / 10 \text { of full scale }
\end{aligned}
$$

b.3.4 Ensure that the coulometer main power switch is on. The coulometer power switch should be on continuously.

b.3.5 Fill the reaction vessel containing a stirring bar to the $25 \mathrm{ml}$ mark with $0.1 \mathrm{M} \mathrm{H}_{2} \mathrm{SO}_{4}$.

b.3.6 Place the reaction vessel on the magnetic stirrer and stir at a constant medium speed.

b.3.7 Add about $0.4 \mathrm{~g}$ of $\mathrm{KBr}$ to the solution (approximately one scoop). Stir until it is dissolved completely.

b.3.8 Rinse the platinum electrodes thoroughly with $0.1 \mathrm{M} \mathrm{H}_{2} \mathrm{SO}_{4}$, then place the electrodes into the reaction vessel. Ensure that the electrode solution $\left(0.1 \mathrm{M} \mathrm{H}_{2} \mathrm{SO}_{4}\right)$ in the bromine generator is at least $2.5 \mathrm{~cm}$ above the solution level of the reaction vessel. Add $0.1 \mathrm{M} \mathrm{H}_{2} \mathrm{SO}_{4}$ to the bromine generator as required.

b.3.9 Turn on the recorder and start recording. When the line on the chart paper is parallel with the chart paper, simultaneously activate the recorder marker and the coulometer cell switch.

b.3.10 When the recorder pen deflects upward more than $5 \mathrm{~cm}$, deactivate the cell switch, lift the recorder pen, rinse the electrodes with $0.1 \mathrm{M} \mathrm{H}_{2} \mathrm{SO}_{4}$ and promptly place the electrodes into the storage vessel $\left(0.1 \mathrm{M} \mathrm{H}_{2} \mathrm{SO}_{4}\right)$ 
b.3.11 Discard the solution in the reaction vessel and rinse both the vessel and stirbar thoroughly with $0.1 \mathrm{M} \mathrm{H}_{2} \mathrm{SO}_{4}$.

b.3.12 Determine the reaction endpoint by connecting the reaction plateau line to the extrapolation of the deflection line. This should be measured in centimeters

b.3.13 Repeat paragraphs b.3.4 through b.3.11 until two consecutive measurements yield a value that is $\leq 0.4 \mathrm{~cm}$. The average of these values is the blank value.

b.3.14 To ensure that the coulometer is operating properly, add $1 \mathrm{ml}$ of a nominal $2 \mathrm{ppm} \mathrm{N}_{2} \mathrm{H}_{4}$ working solution (or equivalent mole quantity) to the solution in the reaction vessel and repeat paragraphs b.3.4 to b.3.11.

b.3.15 The net reaction time for this test (total distance - blank distance) divided by the chart speed $(\mathrm{cm} / \mathrm{min}$ ) should be $4.0 \pm 0.2$ minute. If the titration time is outside of this range, troubleshoot before proceeding.

b.3.16 To analyze the unknown sample, quantitatively transfer either the entire sample from the impinger, or an aliquot of a volumetrically corrected impinger sample (using $0.1 \mathrm{M} \mathrm{H}_{2} \mathrm{SO}_{4}$ ), from a volumetric flask to the reaction vessel. If required, add $0.1 \mathrm{M} \mathrm{H}_{2} \mathrm{SO}_{4}$ to the $25 \mathrm{ml}$ mark of the reaction vessel. Use a $50 \mathrm{ml}$ volumetric flask for volumetric correction. Repeat paragraphs 4.4.19 to 4.4.24 using additional samples.

b.3.17 A sample set is valid if four consecutive samples are within the error guidelines. The errors for each individual sample must be no more than $\pm 2 \mathrm{ppb}$ from the calculated average value of the sample set if the vapor sample concentration is $\leq 40 \mathrm{ppb}$. If the vapor sample concentration is $>$ $40 \mathrm{ppb}$, the errors for each individual sample must be no more than $\pm 5 \%$ from the average value. If the analyzed values fall outside of these guidelines additional analyses are required until four analyzed values fall within the guidelines.

\section{Calculation of $\mathrm{N}_{2} \mathrm{H}_{4}$ Vapor in Air or Nitrogen}

Perform the following calculation:

$$
\begin{aligned}
& \text { Concentration of } \mathrm{N}_{2} \mathrm{H}_{4} \text { in ppm }(\mathrm{V} / \mathrm{V})=\frac{(\mathrm{L}-\mathrm{B})(0.381)}{(\mathrm{X})(\mathrm{R})(\mathrm{V})} \\
& \qquad \begin{aligned}
\mathrm{L} & =\text { Sample line length in } \mathrm{cm} \\
\mathrm{B} & =\text { Blank line length in } \mathrm{cm} \\
\mathrm{X} & =\text { Chart speed in } \mathrm{cm} / \mathrm{min} \\
\mathrm{R} & =\text { Aliquot } \mathrm{ml} / \text { total liquor volume } \mathrm{ml} \text {, ratio } \\
\mathrm{V} & =\text { sample volume } \mathrm{V} \text { at } 25 \mathrm{C} \text { and } 1 \text { atm from paragraph a.7 }
\end{aligned}
\end{aligned}
$$




$$
0.381=\frac{(1.00 \mathrm{E}-4 \mathrm{amp})(60.0 \mathrm{sec} / \mathrm{min})(24.5 \mathrm{l} / \mathrm{mole})(1.00 \mathrm{E} 6 \mu \mathrm{l} / \mathrm{l})}{\left(9.65 \mathrm{E} 4 \mathrm{amp} \mathrm{sec} / \mathrm{mole} \mathrm{e}^{-}\right)(4.00 \mathrm{~mole} \mathrm{e}-/ \mathrm{mole} \mathrm{MMH})}
$$

\subsubsection{Shutdown Procedure}

\section{(a) Reference Gas Generator Shut Down}

When the system is ready for shut down

1. Take the permeation source out of the oven and store it properly as described in "Tube handling and storage" that comes with your permeation source.

2. Purge the system with inert gas for at least $30 \mathrm{~min}$ at a rate of at least $100 \mathrm{cc} / \mathrm{min}$. This will keep the system from being contaminated the next time it is run.

3. Turn the power switch off and store properly.

Note:

Do not under any condition leave the permeation source in the oven when it is not running. Failure to store permeation sources properly will contaminate the system and may damage it.

\section{Storage}

4. Unhook - diluent In, Vent, Span Gas Out. Leave all ports open.

5. Shut down power.

6. Unplug electrical connection.

7. Cover instrument and store in a clean and dry place.

\section{(b) Kintek 491 M-HG (Humidifier) Shut Down}

1) Reduce the saturation pressure to 0 .

2) Reduce $F_{H}$ to about $0.25 \mathrm{I} / \mathrm{min}$.

3) Set the RUN/STANDBY switch to STANDBY.

4) Set the ON/OFF switch to OFF

5) Allow about 2 hours for cool down before removing unmetered dilution flow. 


\section{VERIFYING GAS CONCENTRATION: COULOMETRIC TITRATION SYSTEM}

\subsection{Introduction}

The coulometric titration system was chosen as the method for verifying the gas concentration from the Kintek standard gas generation system. The ORNL coulometric titration system was based on the design used by Wyatt et al. ${ }^{4}$ Improvements were made in the original design by using higher performance integrated circuit components (e.g., use of instrumentation amplifier with higher input impedance and lower bias current) and capability for interfacing to a computer.

Note that coulometric titration is only used to periodically assess the performance of the Kintek reference gas generation system, and is not required for hydrazine monitor calibrations. One advantage of using coulometric titration for verifying the concentration of the reference gas is that it is a primary standard (if used for simple solutions), thereby guaranteeing, in principle, that measurements will be traceable to SI units (i.e., to the mole).

\subsection{The Coulometric Titration System}

The coulometric titration system (Fig. 4.1) consists of an electrolysis cell or a reaction vessel containing $40 \mathrm{~mL}$ of $0.1 \mathrm{M}$ sulfuric acid to which $0.4 \mathrm{~g}$ of potassium bromide has been added. The vessel also contains a bromine generator electrode consisting of a glass tube with a fritted bottom to which electrolysis electrodes are mounted parallel to each side of the frit. (Details of the bromine generator electrode design is shown in Fig. 4.2.) A few milliliters of the $0.1 \mathrm{M}$ sulfuric acid solution are also placed in the fritted glass tube. The level of electrolyte in this tube is kept higher than the level of the solution in the electrolysis cell to assure that no electrolysis solution flows into the tube. The sensing electrode is a dual platinum foil electrode.

The coulometer printed circuit board is shown in Fig. 4.3. It consists of a constant current generator and a sensing circuit. The constant current source is capable of generating a current in the range of $0-1 \mathrm{~mA}$. However, in the present application, the current has been adjusted such that the coulometer applies exactly $0.1 \mathrm{~mA}$ to the bromine generator. The sensing circuit is basically a conductivity measuring circuit, and is used to detect the point at which all the hydrazine in the solution is used up. After this point, free bromine begins to build up in the solution. The output voltage of the sensing circuit, whose input is connected to the sensing electrodes, is proportional to the bromine concentration in the solution.

The circuit diagram for the coulometer is shown in Fig. 4.4. A laboratory setup of the complete system is shown in Fig. 4.5.

The coulometric measurement method titrates hydrazine with electrochemically generated bromine. A great advantage of the method is the elimination of the need to run multiple standards to obtain a calibration curve for the determination of the concentration of the analyte. Another significant advantage is that the bromine required is generated electrochemically, as needed, from potassium bromide and used immediately. There is no need to keep a supply of free, chemically unstable, and corrosive bromine around. Since the amount of bromine produced can be calculated directly from the electrolysis time and current, the following equation can be used to calculate the amount $\boldsymbol{m}$, in grams of hydrazine in the solution:

$m=A^{*} M *\left(t_{s}-t_{b}\right) /(n * F)$ 
Where

$\boldsymbol{M}$ is the molecular weight of hydrazine, here 32.05 grams $/ \mathrm{mole}$;

$\boldsymbol{A}$ is the current applied to the bromine generator cell in amperes (coulombs/sec), (here $0.1 \mathrm{~mA}$ );

$\boldsymbol{t}_{\boldsymbol{s}}$ and $\boldsymbol{t}_{\boldsymbol{b}}$ are the times (in seconds) to the break point, as shown by the output of the sensing circuit (see

Fig. 4.6), of the sample (solution containing the hydrazine) and blank (solution containing no hydrazine) respectively;

$\boldsymbol{n}$ is the number of moles of bromine required to react with (oxidize) one mole of hydrazine (here, 4).

F is Faraday's constant, 96,500 coulombs/mole of electrons.

Figure 4.6 shows a typical recorder output.

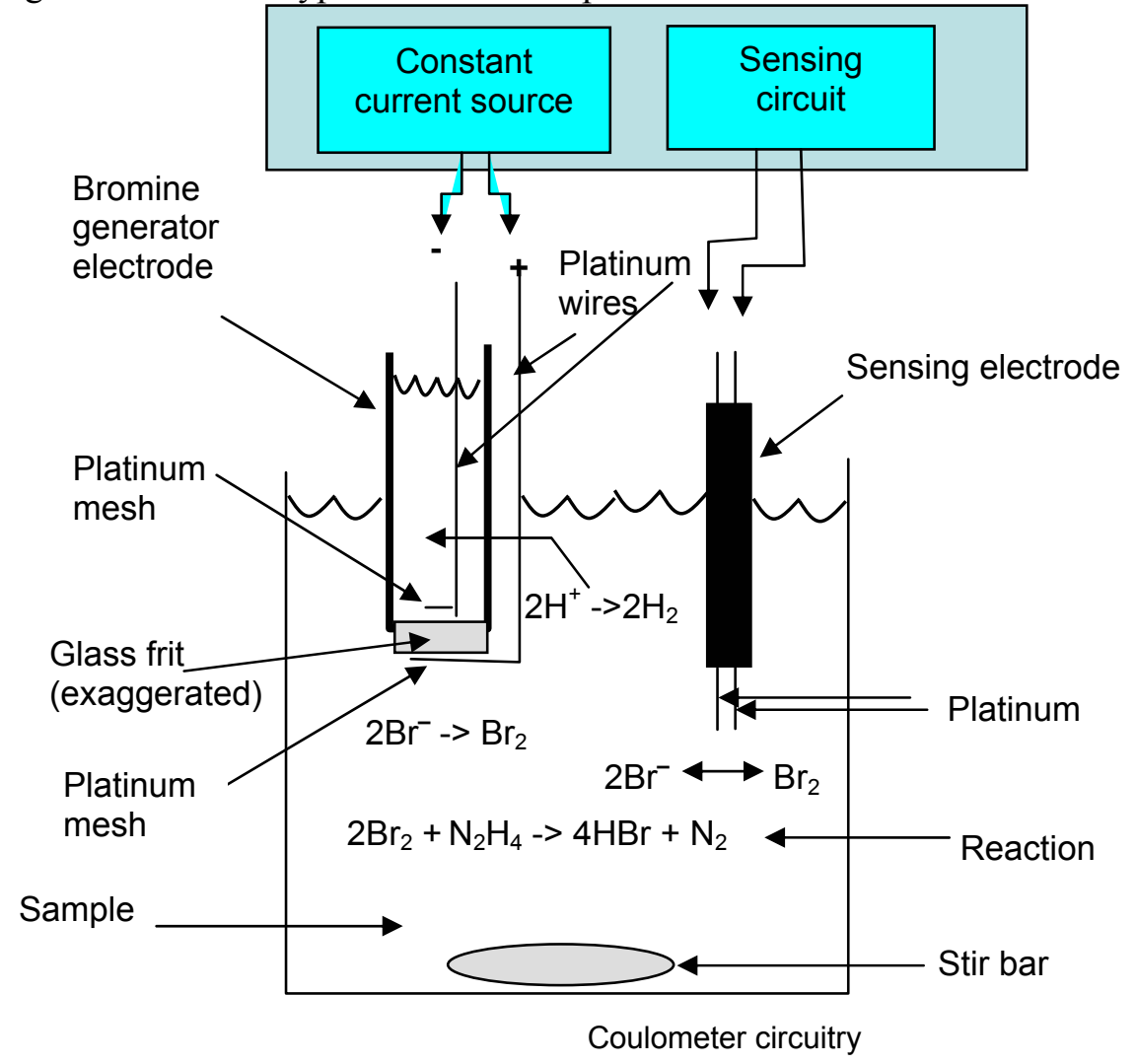

Fig. 4.1 The electrolysis cell and coulometer
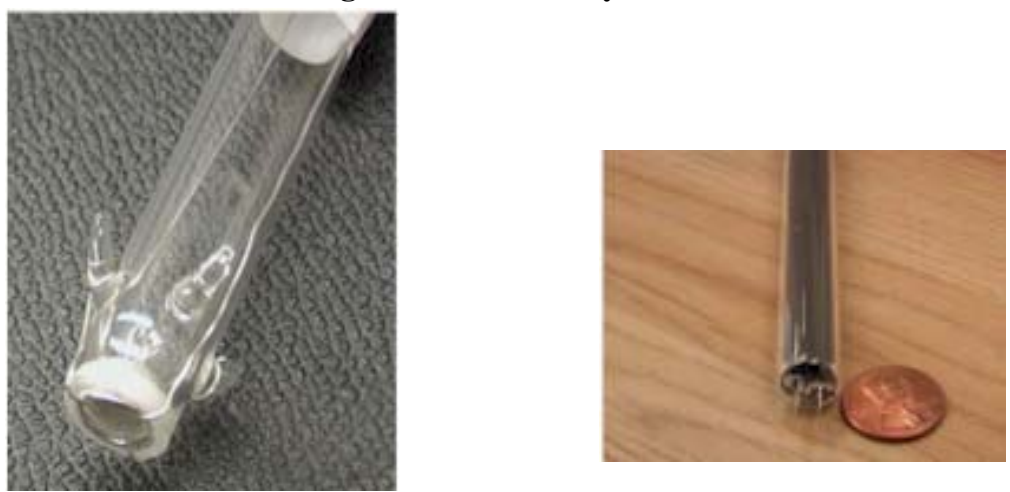

Fig. 4.2 Bromine generator electrode (left) and sensing electrode (right). The two electrodes are approximately the same size, but the top electrode has been exaggerated to show the design. 


\subsection{Colulometer Calibration}

A calibration of the coulometer was performed with a $10 \mathrm{k} \Omega$ resistor (simulating the electrolysis cell) and an HP34401A 5 1/2-digit multimeter connected in series with the resistor. In this way, an accurate measurement of the true electrolysis current could be obtained while observing the reading on the frontpanel meter. The coulometer was turned on and warmed up for an hour prior to taking readings.

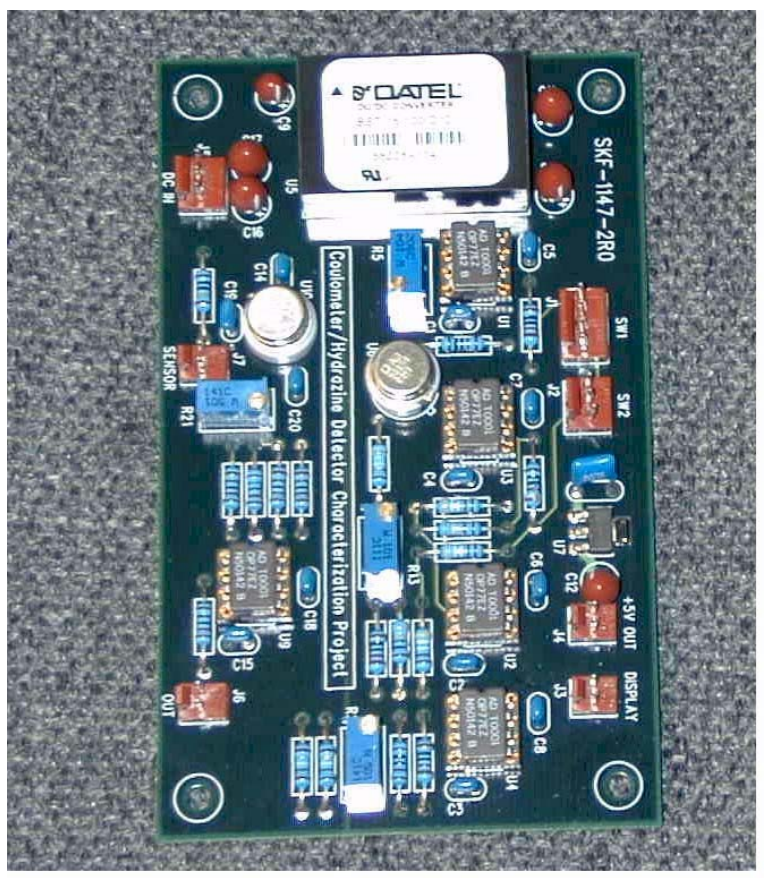

Fig. 4.3 Coulometer printed circuit board (bromine generator and sensing circuit).

The current was adjusted downwards in $0.1000 \mathrm{~mA}$ steps and the panel meter readings were recorded as shown in Table 4.1. The results show that the panel meter reading has very good agreement with the calibrated HP multimeter readings. Further analysis of the circuit showed that the electrolysis current measurement has an error that will change with the electrolysis cell resistance due to the effect of the input impedance of the amplifier measuring the voltage drop across the current-sensing resistor.

However, given the amplifier used in this circuit, this error will always be less than $1.5 \%$ of reading if the cell resistance does not exceed $10 \mathrm{k} \Omega$. 
Table 4.1. HP multimeter readings vs coulometer panel meter readings.

\begin{tabular}{|c|c|}
\hline HP METER READING & COULOMETER PANEL READING \\
\hline $1.0000 \mathrm{~mA}$ & $1.000 \mathrm{~mA}$ \\
\hline $0.8999 \mathrm{~mA}$ & $0.900 \mathrm{~mA}$ \\
\hline $0.8003 \mathrm{~mA}$ & $0.800 \mathrm{~mA}$ \\
\hline $0.7000 \mathrm{~mA}$ & $0.700 \mathrm{~mA}$ \\
\hline $0.6000 \mathrm{~mA}$ & $0.600 \mathrm{~mA}$ \\
\hline $0.5000 \mathrm{~mA}$ & $0.500 \mathrm{~mA}$ \\
\hline $0.4000 \mathrm{~mA}$ & $0.400 \mathrm{~mA}$ \\
\hline $0.3000 \mathrm{~mA}$ & $0.300 \mathrm{~mA}$ \\
\hline $0.2000 \mathrm{~mA}$ & $0.199 \mathrm{~mA}$ \\
\hline $0.1000 \mathrm{~mA}$ & $0.099 \mathrm{~mA}$ \\
\hline
\end{tabular}




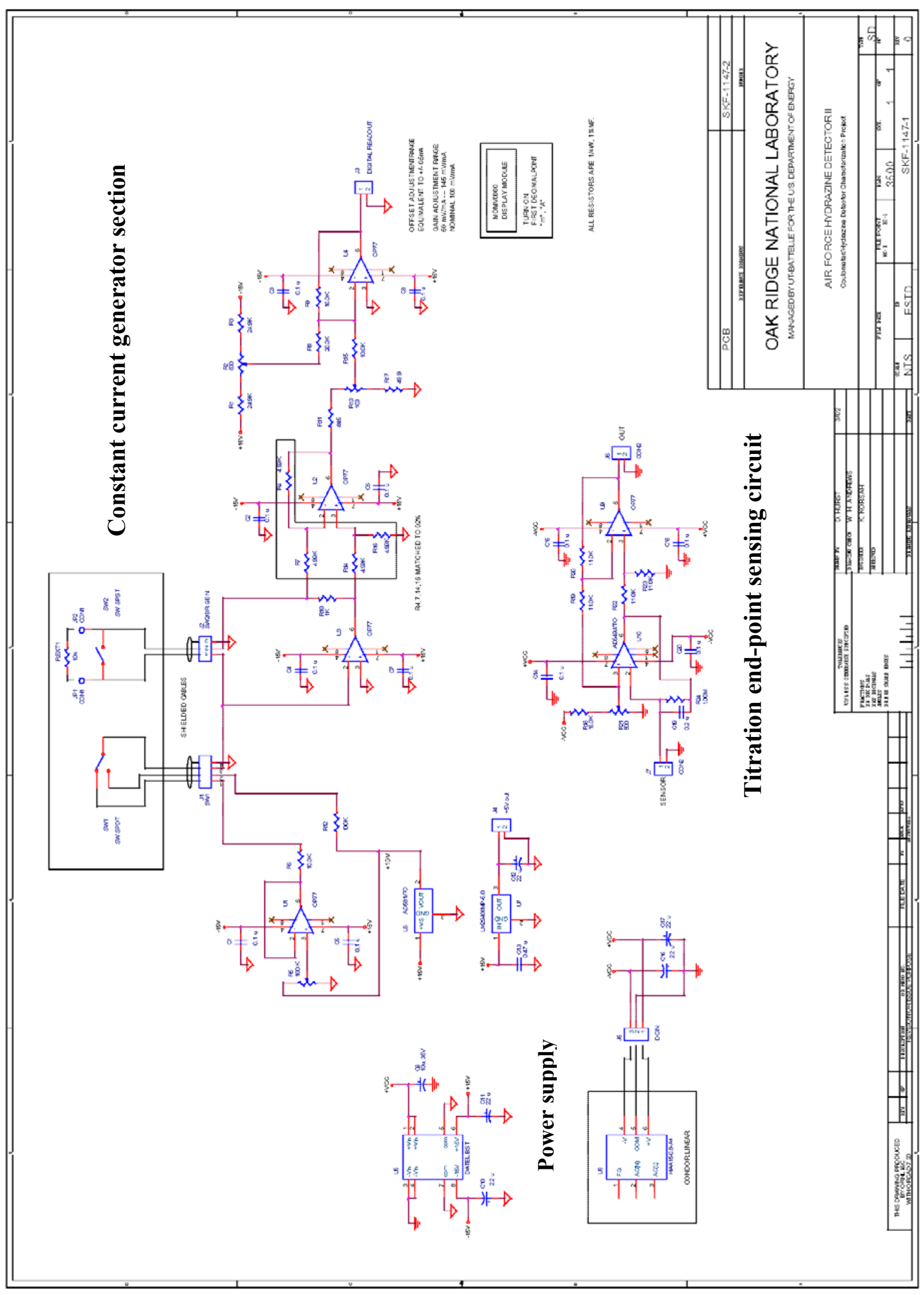

لَّ 


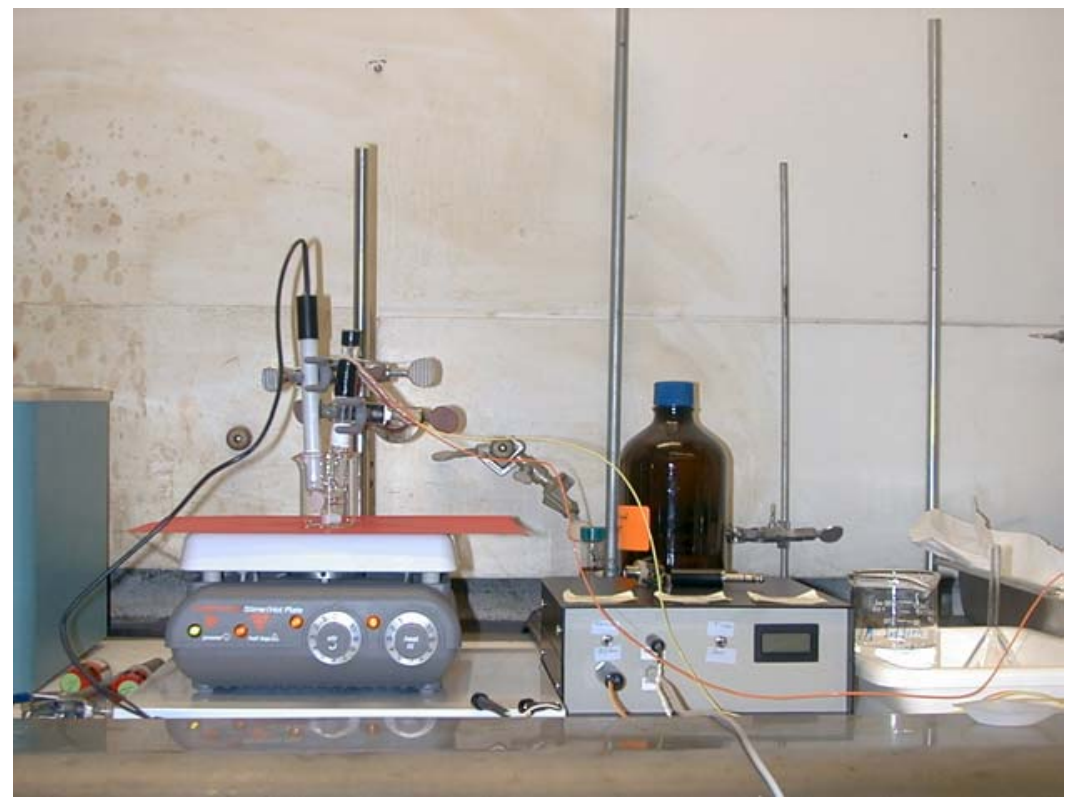

Fig. 4.5 Laboratory setup of the ORNL coulometric titration system

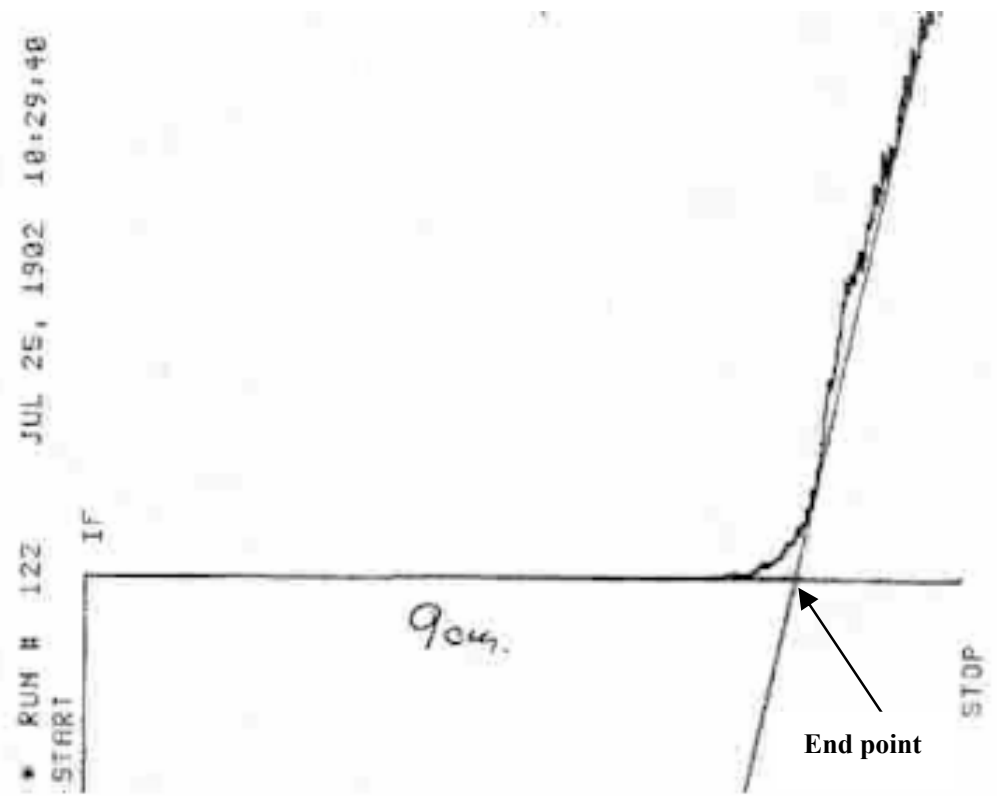

Figure 4.6. Typical recorder output of a coulometric titration run. 


\section{TRACEABILITY ANALYSIS}

Figure 5.1 shows the traceability of the gas concentration generated by the Kintek 491 M-B Reference Gas Generation System.

Traceability is maintained by using NIST certified procedures in calibration of the following:

a) Kintek 491 M-B system's flowmeters, permeation oven temperature controller, permeation tube permeation rates, and hygrometer;

b) volume of reference gas sampled by each impinger using the impinger sampling system's rotameter to measure the flow rate and timer to measure the flowing time;

c) current delivered by the coulometer;

d) mass of hydrazine in the impinger sample based on the charge necessary for the titration of the sample using coulometric titration system's coulometer to generate the constant current and the integrator to measure the titration time. (The time is measured by using the integrator's chart recorder and determining the total time of titration based on the chart speed and the length of chart to the titration endpoint.);

(e) standard hydrazine sulfate solution used to calibrate the coulometric titration system.

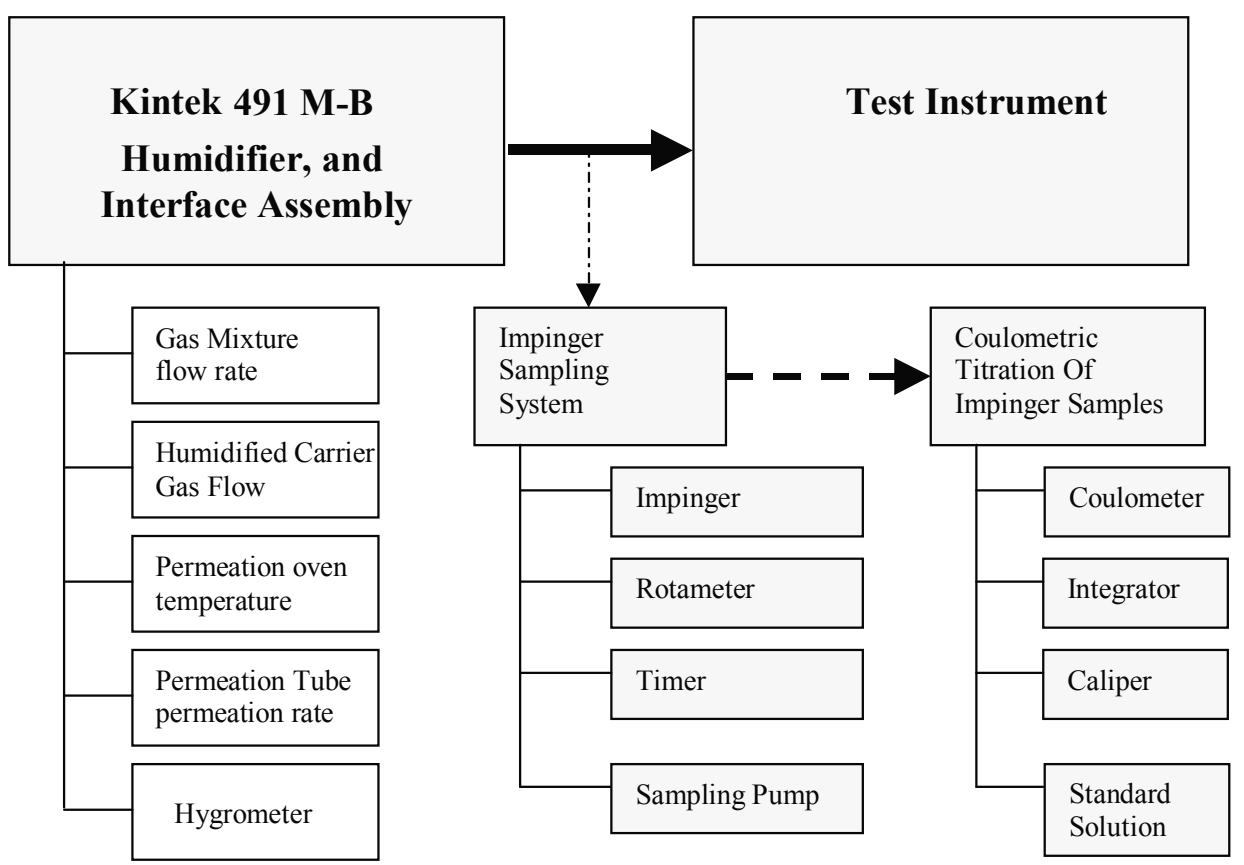

Fig. 5.1 Diagram depicting traceability of the gas concentration generated by the Kintek 491 M-B Reference Gas Generation System. 


\section{CALIBRATION STUDIES USING THE ORNL SETUP}

\subsection{Calibrating the Kintek 491 M-B Reference Gas Generation System}

ORNL performed several studies to evaluate the calibration of hydrazine detectors using the Kintek 491MB reference gas generation system. The Kintek 491MB system includes the 491MB gas mixture generator, the humidifier module (491M-HG), and the sample atmosphere interface module (491M-IM). This system is used to produce the gas mixture that serves as the reference concentration in the calibration of hydrazine gas detectors.

The ORNL calibration method uses the $491 \mathrm{MB}$ permeation tube system to generate the reference gas. The hydrazine concentration of the reference gas generated by the $491 \mathrm{MB}$ system is given by the equations:

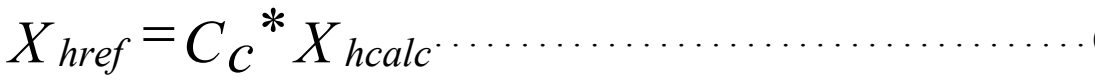

$$
\begin{aligned}
& X_{\text {hcalc }}=\frac{E^{*} K_{0}}{F_{T}}
\end{aligned}
$$

and

$$
K_{0}=\frac{22.4}{M}
$$

where

$\mathrm{X}_{\text {hcalc }}$ is the calculated hydrazine concentration of the $491 \mathrm{M}-\mathrm{B}$ gas mixture generator alone

$\mathrm{X}_{\text {href }}$ is the hydrazine concentration of the reference gas generated by the $491 \mathrm{MB}$ system as measured using coulometric titration.

$\mathrm{C}_{\mathrm{c}}$ is the Kintek $491 \mathrm{MB}$ system calibration factor determined by coulometric titration of impinger samples

$\mathrm{E}$ is the emission rate of component compound (hydrazine) from the permeation tube in $\mathrm{ng} / \mathrm{min}$ $\mathrm{K}_{0}$ is the conversion factor which converts the emission rate from weight basis to volume basis

$\mathrm{F}_{\mathrm{T}}$ is the total reference gas mixture flow rate in liters/min at standard temperature and pressure (STP)

$\mathrm{M}$ is the molecular weight of the component compound (hydrazine)

The factor $\mathrm{C}_{\mathrm{c}}$ is the Kintek $491 \mathrm{M}-\mathrm{B}$ system calibration factor. It is determined by creating a calibration curve using coulometric titration of impinger samples of the test atmosphere generated by the $491 \mathrm{MB}$ system. The coulometric titration of these impinger samples collected by passing a measured volume of the test atmosphere through the impingers is used to determine the concentration of the reference atmosphere. The gas detectors are then used to sample this same test atmosphere. This process is repeated for three or more different gas concentrations and the concentrations determined by coulometric titration $\left(X_{\text {href }}\right)$ are plotted against the calculated output concentration $\left(X_{\text {hcalc }}\right)$ of the $491 \mathrm{M}-\mathrm{B}$ gas mixture generator. A linear regression analysis of the plot is then used to determine the value of $\mathrm{C}_{\mathfrak{c}}$. An example of this plot is shown in Fig 6.1. The $\mathrm{C}_{\mathrm{c}}$ value shown is the slope 0.66 


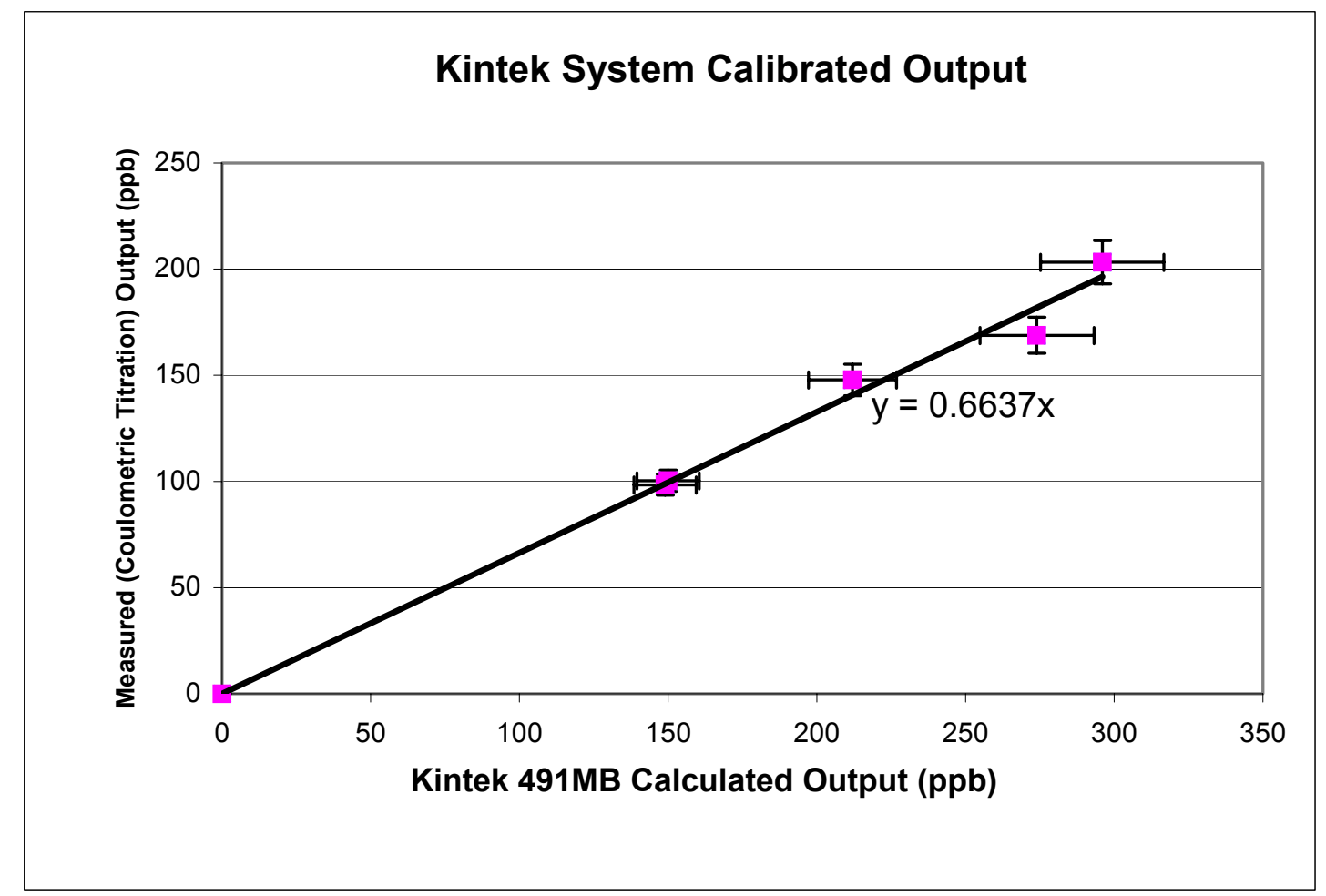

Fig. 6.1. Determination of the calibration factor $\left(C_{c}\right)$ for the Kintek 491 M-B using the coulometer titration system.

\subsection{Calibrating the MDA 7100: Characterization of Relative Humidity Effects}

When the ORNL calibration method is used to calibrate the Zellweger MDA 7100 hydrazine detectors, it is necessary to obtain a humidity effect characterization equation to be used in the calibration procedure. This is necessary because the 7100 is affected by the relative humidity of the gas mixture being sampled and the relative humidity of the environment of the chemcassette. The chemcassette is a chemically coated paper tape which reacts with the hydrazine and changes color proportional to the hydrazine concentration. Zellweger calibrates the MDA 7100 with a gas mixture which is kept at a relative humidity of $50 \%+5 \%$. Zellweger and NASA have done studies that document the effects of changes in the relative humidity on the performance of the 7100. ORNL repeated this study and obtained results which agreed with the Zellweger results and which were a constant multiple of the NASA results. ORNL used its humidity characterization equation to adjust the MDA 7100 readings for the humidity of the gas mixture and used these adjusted results to calibrate the MDA 7100. This process was done with results which were obtained at several different gas mixture relative humidities $(1.3 \%, 30 \%$, and $60 \%)$. No matter what relative humidity ORNL used, the calibration results agreed with the ZA calibration results when the MDA 7100 readings were corrected with the relative humidity characterization equation.

Zellweger's study also showed a relative humidity effect when the relative humidity surrounding the chemcassette was varied. ORNL has not yet determined this relationship so no correction for this affect was done.

Figure 6.2 shows the ORNL relative humidity characterization results and compares the ORNL results to the results of the ZA and NASA studies. The variations in the ZA results at each single gas mixture 
relative humidity show the effects of varying the relative humidity surrounding the chemcassette. The equations on the graph are the linear regression equations for each of the studies. The ZA and ORNL characterization equations are within $\pm 10 \%$ of the average of the two equations over the entire range of the ORNL results. The ZA equation is the linear regression line based on all the ZA data including the variation caused by changes in the relative humidity of the chemcassette environment. Figure 6.3 shows the ORNL relative humidity characterization results graph.

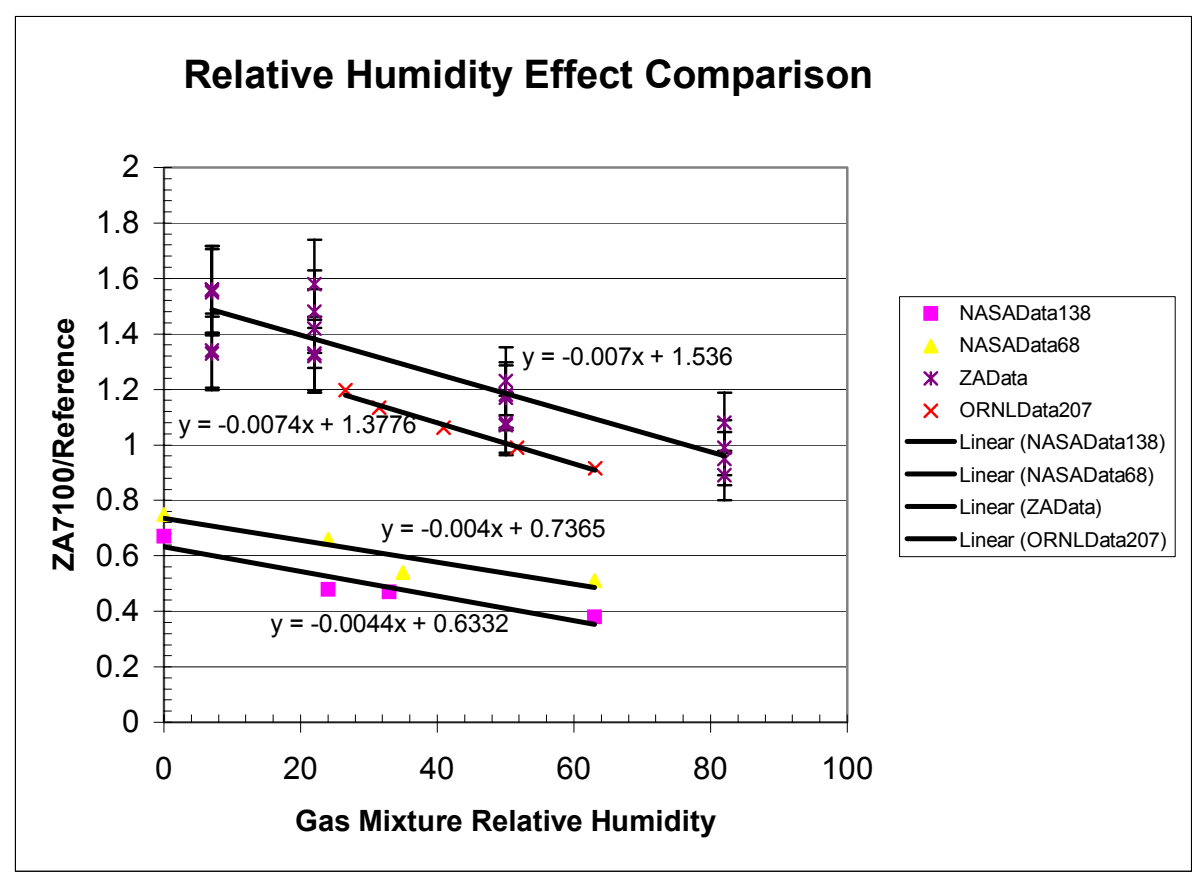

Fig. 6.2. ORNL relative humidity results compared to the ZA and NASA studies (see text).

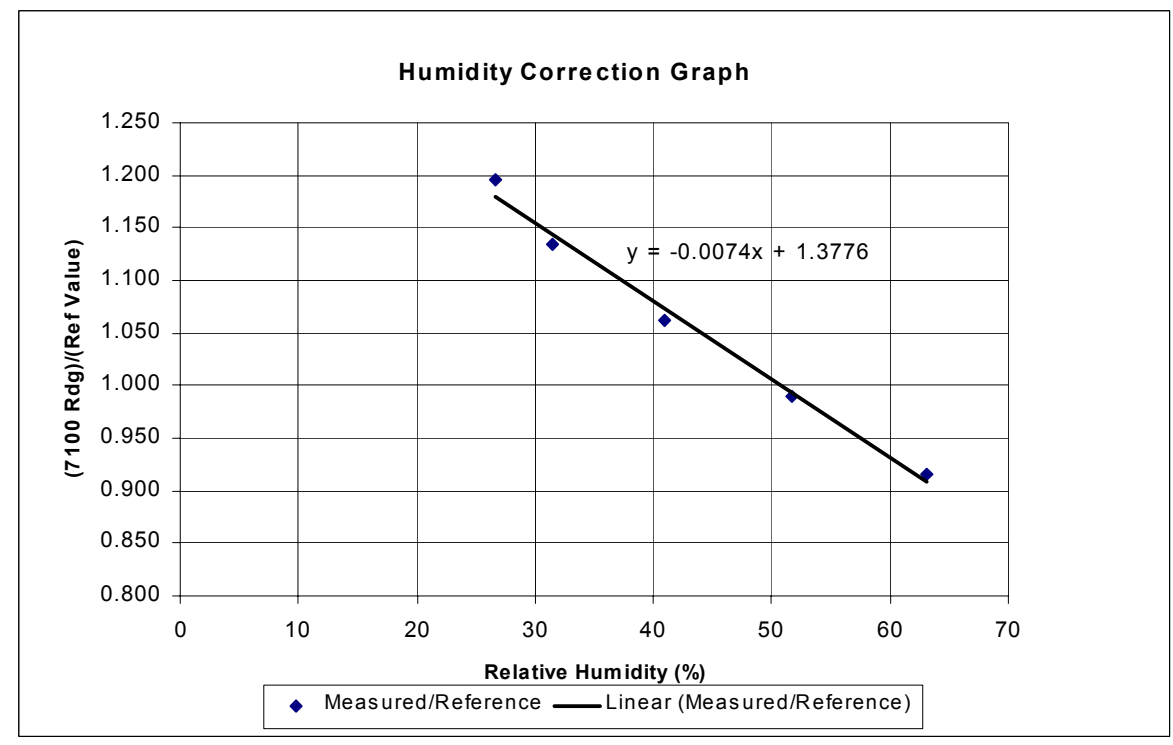

Fig. 6.3. Relative humidity correction graph. 
Using the Kintek 491M-B system calibrated output and the humidity corrected readings for the MDA 7100, ORNL performed calibrations of two different MDA 7100's (SN 5148 and SN 4260) and compared these results to the ZA calibrations of the same 7100s with the same serial numbers. As shown in figures 6.4 and 6.5, the results of these ORNL calibrations agreed with the ZA calibration results when the MDA 7100 readings were corrected with the ORNL relative humidity characterization equation.



Fig. 6.4. Comparison of ORNL's humidity-corrected calibration data with corresponding data for the MDA 7100 (serial \# 5148).

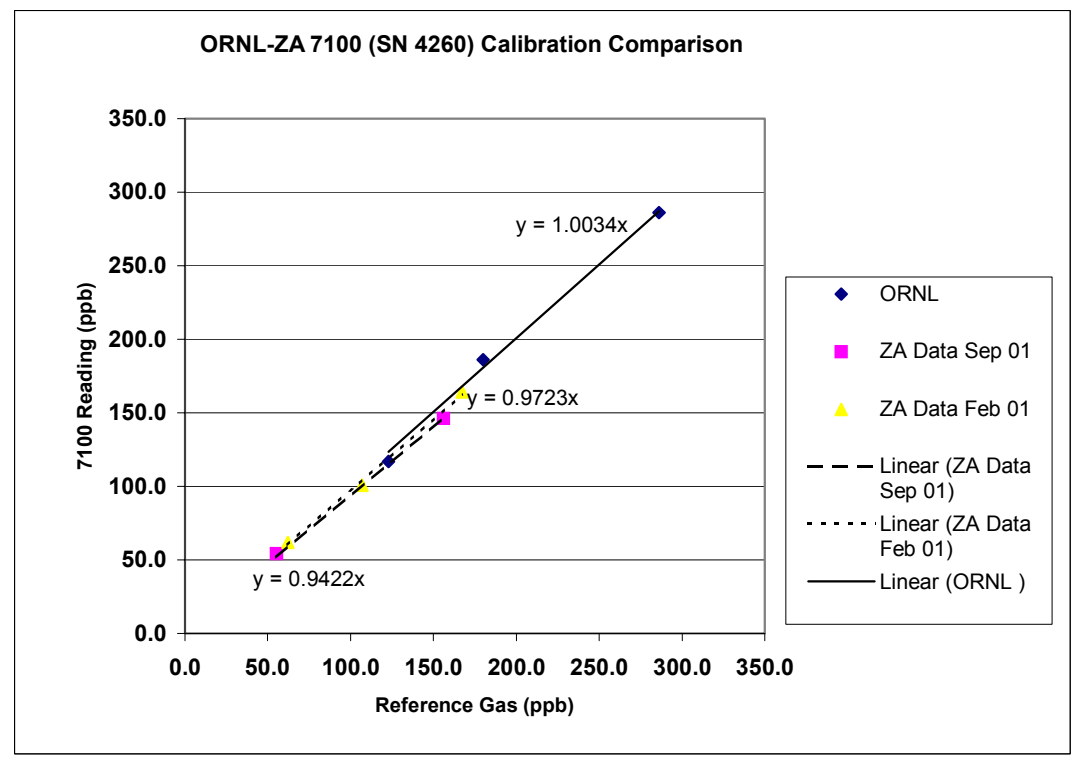

Fig. 6.5. Comparison of ORNL's humidity-corrected calibration data with corresponding data for the MDA 7100 (serial \# 4260). 


\subsection{Calibrating the Interscan 118PQ Sensors Using the Kintek 491 M-B}

ORNL also used the calibrated Kintek 491M-B system to perform calibration tests on two Interscan 118PQ sensors using the Interscan 4187 gas detector. Only one of the resulting graphs are shown below because the results of the other 118PQ indicated that this sensor was badly out of calibration and needed to be repaired or replaced. No humidity correction was performed on the Interscan 4187 data because the measurements with the Interscan instruments did not show a measurable effect when the relative humidity of the gas mixture was varied. If an effect exists, it does not appear to be large enough to cause the 4187 readings to change more than their specified uncertainty.

The Interscan 4187 has both a high range ( 0 to $2000 \mathrm{ppb}$ ) and a low range ( 0 to $100 \mathrm{ppb})$ and the detector uncertainty specifications are stated as $\pm 2 \%$ of full scale. For the results shown in Figure 6.6 the two values above $100 \mathrm{ppb}$ were measured using the high range ( 0 to $2000 \mathrm{ppb}$ ) and are within the specified uncertainty for this range. However, the data point on the graph that is less than $100 \mathrm{ppb}$ (which was measured using the low range) is not within the specified uncertainty for the low range on this detector. This result was discussed with cognizant personnel at Kennedy Space Center who have performed evaluations of the Interscan instruments for NASA. The researchers' experience indicated that the Interscan units were not reproducible when new sensors were used and that they had discovered that the Interscan units read incorrectly on the low range because of the presence of carbon dioxide. KSC personnel also indicated that NASA is phasing out the use of these Interscan detectors.

ORNL did not test the carbon dioxide effect, but it was found that the units did not read zero when a test gas containing no hydrazine was sampled. Repeating the tests after the unit was re-zeroed according to Interscan's specifications still resulted in readings of $10 \pm 3$ ppb each time a test atmosphere containing no hydrazine was sampled. Since the low range for the Interscan 4187 using a 118 PQ sensor is 0 to $100 \mathrm{ppb}$ and the specified uncertainty is only $\pm 2 \mathrm{ppb}$, these variations indicate that additional evaluation of the low range performance of the Interscan units is needed. Therefore, more study of these units is needed to determine their performance and the best procedure to calibrate and use them.

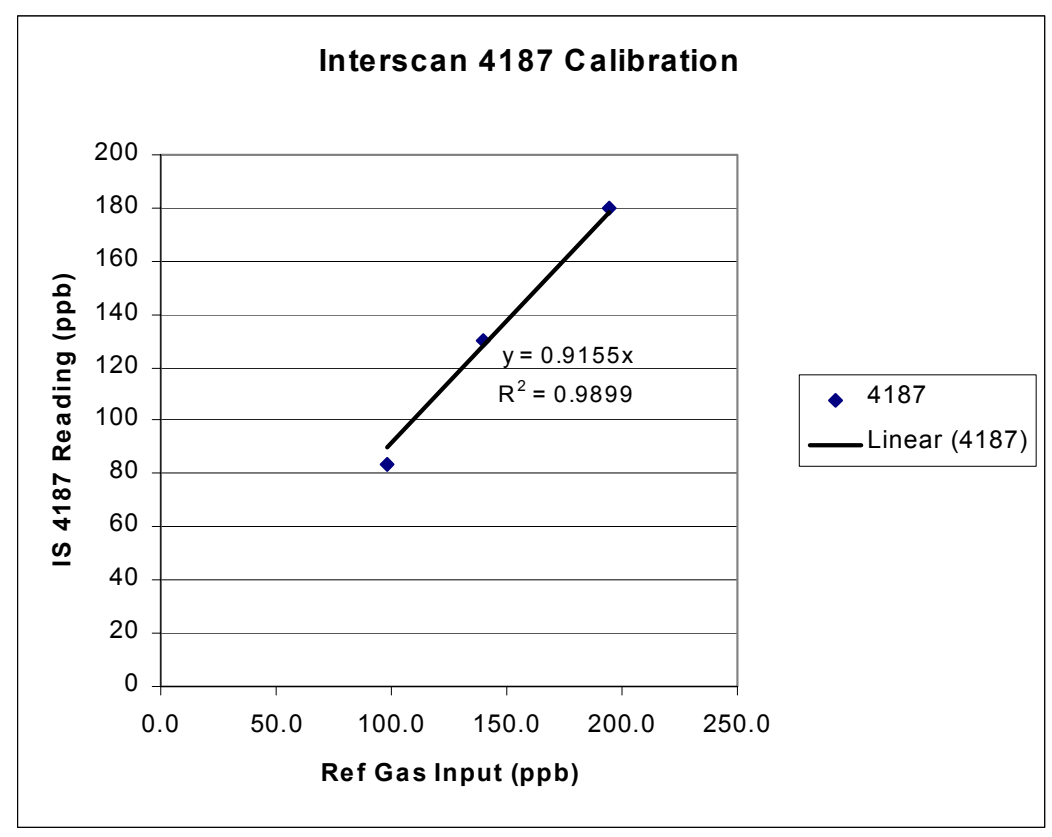

Fig. 6.6. ORNL calibration of Interscan 4187 hydrazine detector. 


\section{AUTOMATION FEASIBILITY ANALYSIS}

\subsection{MDA 7100 Communication Capability}

ORNL has investigated the communication capabilities of the 7100 toxic gas monitor with an external device such as a computer. The model MDA 7100 can be equipped with an RS-232 serial communication interface. This interface can be used both to program an instrument as well as to receive data that an instrument will generate during monitoring. All programmable features that are accessible from the front panel are also programmable through the serial interface. These features include: gas selection, alarm levels, enabling or disabling the printer, resetting alarms, as well as additional features which are not accessible from the front panel. The full capabilities are given in Table 7.1.

Table 7.1. Serial Communication Commands for the 7100

\begin{tabular}{|l|l|}
\hline \multicolumn{1}{|c|}{ 7100 INPUT COMMANDS } & \multicolumn{1}{c|}{ 7100 REQUESTED OUTPUTS } \\
\hline Set the range of the 4-20 mA output & $\begin{array}{l}\text { Get the highest average concentration for one } \\
\text { sample period. }\end{array}$ \\
\hline $\begin{array}{l}\text { Set the alarm level, concentration, Enable/Disable } \\
\text { Audio. }\end{array}$ & Get the highest 15-min. average. \\
\hline Start analysis and continue until requested to stop. & Get the elapsed 8h average. \\
\hline Change to a different gas & Get the range of the 4-20 mA output. \\
\hline $\begin{array}{l}\text { Set the analysis period (restricted to 10 or 15 } \\
\text { minute period). }\end{array}$ & $\begin{array}{l}\text { Get the gas type the instrument is currently set for } \\
\text { monitoring. }\end{array}$ \\
\hline & $\begin{array}{l}\text { Get the alarm set point the instrument is currently } \\
\text { set to. }\end{array}$ \\
\hline & $\begin{array}{l}\text { Get the status of the instrument (i.e., monitoring } \\
\text { mode, idle, or waiting mode). }\end{array}$ \\
\hline & $\begin{array}{l}\text { Get the analysis period the instrument is currently } \\
\text { set to (10 or 15-min.). }\end{array}$ \\
\hline
\end{tabular}

\subsection{Kintek 491 M-B Communication Capability}

Although the Kintek 491 M-B has a serial port at the back of the unit, it is not typically marketed with the internal interface wiring necessary for serial communication. Depending on the level of automation desired, this internal wiring can be performed and documented by ORNL

\subsection{Recommendations for Automation of Hydrazine Monitor Calibrations}

Based on the communication capabilities of the MDA 7100 and the Kintek 491 M-B as discussed above, the following options are suggested for automating the calibration procedures:

- Technical Order (T.O.) Automation:

A check list of the calibration procedure to ensure that the operator performs the necessary steps in the necessary order. 
- Data Analysis Automation:

At this level of automation, calibration data will also be generated manually as in the case of T.O. Automation. In addition, an automated excel spreadsheet would be created to do the data analysis and create the calibration certificates. A statistical process control spreadsheet would be created to generate control charts for the Kintek reference gas generator and for any test instruments that are on a calibration recall schedule.

- $\quad$ Automation of Data Acquisition:

At this level of automation, data from the Kintek gas generation system as well as environmental parameters would be read directly into the data analysis spreadsheet by the computer. The required data to be acquired are: total flow of reference gas from the Kintek, temperature and relative humidity of reference gas in interface module, temperature, pressure, and relative humidity of the hood where the instruments are being used. 


\section{CONCLUSIONS AND RECOMMENDATIONS}

The study documented in this report constitutes the first phase of the Hydrazine Detector Characterization and Calibration Project. A methodology for calibrating model MDA 7100 hydrazine detectors in the United States Air Force inventory has been developed. The calibrating procedure is an improvement (lower uncertainty, lower calibration time, faster turn-around time) over the method currently used by Zellweger Analytics to calibrate these monitors. This methodology uses the Kintek model $491 \mathrm{M}$-B permeation-tube-based gas generator as the standard. The methodology can easily be adapted for other types of hydrazine detectors.

Several significant findings have been documented during the course of this project. These are as follows:

1) The Kintek system output concentration is less than the calculated output of the generator alone but can be calibrated as a system (including effect of tubing, etc) by using coulometric titration of gas samples collected with impingers.

2) The calibrated Kintek system output concentration is reproducible even after having been disassembled and moved and reassembled.

3) The uncertainty of the reference gas concentration generated by the Kintek system is less than half the uncertainty of the Zellweger Analytics' (ZA) reference gas concentration and can be easily lowered to one third or less of the ZA method by using lower-uncertainty flow rate or total flow measuring instruments.

4) The largest sources of uncertainty in the current ORNL calibration system are the permeation rate of the permeation tubes and the flow rate of the impinger sampling pump used to collect gas samples for calibrating the Kintek system. Both of these can be reduced by upgrading the measurement equipment, as stated in (3).

5) The coulometric titration technique can be used to periodically assess the performance of the Kintek system and determine a suitable recalibration interval.

6) The Kintek system has been used to calibrate two MDA 7100s and an Interscan 4187 in less than one workday. The system can be upgraded (e.g., by automating it) to provide more calibrations per day.

7) The humidity of both the reference gas and the environment of the Chemcassette affect the ZA 7100 hydrazine detector's readings. However, ORNL believes that the environmental effect is less significant than the effect of the reference gas humidity.

8) The ORNL calibration method based on the Kintek 491 M-B gas standard can correct for the effect of the humidity of the reference gas to produce the same calibration as that of Zellweger Analytics (ZA). ZA calibrations are typically performed at $45 \%$ - $55 \%$ relative humidity.

9) Tests using the Interscan 4187 showed the instrument was not accurate in its lower $(0-100 \mathrm{ppb})$ range. Subsequent discussions with Kennedy Space Center (KSC) personnel also indicated that similar behavior have been observed. In particular, the Interscan units used in their study were not reproducible when the sensors in the units were replaced with new ones. KSC had discovered that the Interscan units read incorrectly on the low range because of the presence of carbon dioxide. 
ORNL did not test the carbon dioxide effect, but it was found that the units did not read zero when a test gas containing no hydrazine was sampled. According to the KSC personnel that ORNL had these discussions with, NASA is phasing out the use of these Interscan detectors.

Based on the findings identified from these studies, the following recommendations are suggested:

a) The coulometric calibration procedure should be used to perform additional calibrations of the Kintek system to establish a base set of data to be used in statistical process control of it.

b) The system should be used to calibrate and recalibrate the MDA 7100's and other hydrazine detectors to establish a baseline set of data to be used in statistical process control and establish the methods for detecting the need for recalibration and calibration recall intervals of each type of detector.

c) The time per calibration and turnaround time to calibrate and instrument should be further reduced by automating the data collection and analysis procedures as well as the reporting.

d) The calibration procedure T.O. should be implemented as a fully automated interactive checklist, data acquisition and analysis system. This will reduce the need to repeat calibrations because something that needed to be done was omitted or done incorrectly.

e) The development of a miniaturized version of the coulometric titrator that could be placed in-line between the reference gas generation system and the detector should be considered. Such a system is likely to have much better resolution, reliability, and much lower uncertainty than currently available hydrazine detectors/standards. 


\section{REFERENCES}

1. McKinley, J. J., Model 491 M-B Operation Manual, Kin-Tek Laboratories Inc., LaMarque, TX

2. McKinley, J. J., 491 M Precision Gas Standards Generating System Instruction Manual--491M-HG

Humidification Module, Kin-Tek Laboratories Inc., LaMarque, TX

3. S. L. Rose and J. R. Holtzclaw, A Critical Comparison of Commercially Available Hydrazine Detectors, NRL Report 8848, Naval Research Laboratory, Washington, D. C., March 19, 1985.

4. J. R. Wyatt, S. L. Rose-Pehrsson, T. L. Cecil, K. P. Crossman, N. K. Mehta, and R. Young, Coulometric Method for the Quantification Of Low-Level Concentrations of Hydrazine and Monomethylhydrazine, American Industrial Hygiene Journal (54), June 1993.

5. Young, Rebecca C., Determination Of Concentrations $\mathrm{Of}_{2} \mathrm{H}_{4}$ Or MMH Vapor In Nitrogen Or Air By The Coulometric Titration Method, ACL-SLP-4.2 Rev 6, National Aeronautics and Space Administration, Kennedy Space Center, Florida. 


\section{APPENDIX A}

\section{HYDRAZINE SAFETY PROGRAM}

\section{A.1 Introduction}

Due to the highly toxic nature of hydrazine, ORNL developed a hydrazine safety video to train calibration technicians in order to ensure safe hydrazine calibration operations. It should be emphasized that this safety video has a narrow focus: to provide basic technical information as well as precautions to be taken when handling small quantities of hydrazine (in permeation tubes) during calibration.

\section{A.2 Standards}

The primary component of the safety program is the Health/Environmental hazards of the hydrazine. Hydrazine is a highly hazardous material. The ACGIH Threshold limit value (TLV) is $0.01 \mathrm{ppm}$ and OSHA's Personnel Exposure Limit (PEL) is 1 ppm. Since AFOSH 48-8 states that the most stringent requirement is to be used, this means the ACGIH's TLV is to be the value used to set the Air Force's Occupational Exposure Limits (OEL). In addition, hydrazine has a skin designation. This means that it is easily absorbed through the skin. However, only the liquid phase is easily absorbed and the liquid will be sealed inside teflon permeation tubes. These tubes are not breakable so they should provide an effective means of keeping the liquid hydrazine from contacting the skin. Nevertheless, the tubes should not be handled without wearing protective clothing to both prevent contamination of the tubes and to prevent contact with the skin because of a leaking tube.

The Safety Program and Training is designed to comply with OSHA's 29 CFR 1910 subpart z (Toxic and Hazardous Substances) ${ }^{1}$, and OSHA's 29 CFR 1910.1450 (Hazardous Chemicals in Laboratories). ${ }^{2}$

For the development of the video program, ORNL used the Center for Disease Control's Laboratory Standard Chemical Hygiene Plan as a template ${ }^{3}$. It was modified to be specific to hydrazine as it is to be used in the Air Force Hydrazine Detector Calibration procedures.

\section{A.3 Worst Case Accident Scenarios in Hydrazine Calibration Laboratory}

In order to develop a basis for the level of safety requirements (e.g., personal protective equipment) needed in a calibration laboratory, as well as the level of detail needed for the safety video, ORNL assessed the worst case accident scenarios in a typical calibration room.

Assumptions made are as follows:

Smallest likely laboratory: $15 \mathrm{ft}$ by $20 \mathrm{ft} \times 9 \mathrm{ft}\left(2700 \mathrm{ft}^{3}\right.$, or $\left.76.4 \mathrm{~m}^{3}\right)$

ACGIH TLV: $(8 \mathrm{hrs})=0.01 \mathrm{ppm}\left(0.013 \mathrm{mg} / \mathrm{m}^{3}\right)$.

Odor threshold $\quad=3-4 \mathrm{ppm}$

\footnotetext{
${ }^{1}$ http://www.osha-slc.gov/OshStd_toc/OSHA_Std_toc_1910_SUBPART_Z.html

2 http://www.osha-lc.gov/OshStd_data/1910_1450.html.

${ }^{3}$ http://www.cdc.gov/od/ohs/manual/chemical/chmsaf2.htm
} 


$$
\begin{array}{ll}
\text { LEL } & =2.9 \% \\
\text { Vapor pressure } & =0.013 \mathrm{~atm}(10 \mathrm{~mm} \text { of } \mathrm{Hg}) .
\end{array}
$$

Each hydrazine permeation tube contains about 5 grams or less of liquid hydrazine which is sealed inside teflon cylindrical tubes that allow the hydrazine vapor to permeate at rates controlled by the tube's' temperature. Typical permeation rates are 700 nanograms/minute or less. Calibrations covering the range from $10 \mathrm{ppb}$ to $1 \mathrm{ppm}$ could be done with 3 different rate tubes. For this scenario, ORNL assumed two tubes for each range to be in the room.

Thus, total mass of hydrazine on premises at any time $=30 \mathrm{~g}$

Although it appears very unlikely that more than one tube would leak all of its contents at the same time, ORNL evaluated what would happen if all six tubes did leak at the same time. This would enable the training program to be based on the worst possible conditions that could exist.

\section{Worst Case Scenario, Maximum Possible Air Concentration}

Assuming a complete spill, $100 \%$ evaporation and no losses, $30 \mathrm{~g}$ of hydrazine was calculated to be equivalent to $302 \mathrm{ppm}$. However, hydrazine does not volatilize instantly, so the actual air concentration will be less.

\section{Estimation of Evaporation Rate (using EPA Hummel-Braun-Fehrenbarcher model):}

Given the density of hydrazine of $1 \mathrm{~g} / \mathrm{cc}$, and assuming that a spill of the chemical will give rise to a circular spot size $1 \mathrm{~mm}$ deep, the diameter of the spill will be $19.5 \mathrm{~cm}$ with an area $0.03 \mathrm{~m}^{2}$. Assuming an ambient temperature of $68{ }^{\circ} \mathrm{F}$ and $35 \mathrm{ft} / \mathrm{min}$ air velocity over pool, the evaporation rate was calculated to be $17.3 \mathrm{mg} / \mathrm{min}$. Depending on the actual spill size (mass, surface area), the air velocity, and temperature, a hydrazine spill may take hours to evaporate.

\section{a) Maximum Steady State Evaporation (assuming estimated evaporation rate as above):}

For $5 \mathrm{~g}$ (1 tube) spill. 2 ppm

For $30 \mathrm{~g}$ (all 6 tubes). 5 ppm

Assuming flow rate dilution air of $360 \mathrm{ft}^{3} / \mathrm{min}$ and a mixing factor $\mathrm{K}^{*}$ of 4 :

For a $5 \mathrm{~g}$ spill, the hydrazine concentration in the room will be about $0.25 \mathrm{ppm}$ after $1 \mathrm{~min}$. For a $30 \mathrm{~g}$ spill, the hydrazine concentration will be about $0.64 \mathrm{ppm}$ after $1 \mathrm{~min}$.

\section{A.4 Quality Assurance and Chemical Hygiene Plan}

The primary Quality Assurance (QA) document used for this project was the ORNL Instrumentation and Controls (I\&C) Division's QA-IC-OP57, “Assessment of Projects, Work for Others (WFO), and Cooperative Research (CRADA) Plans and Proposals." This document ensures that the Principal Investigator(s) or Project Manager(s) has addressed key issues in the preparation of project plans and proposals. In addition, methods of operation as specified in the Division's chemical hygiene plan was followed. This plan was written in accordance with 29 Code of Federal Regulations (CFR) 1910.1450, "Occupational Exposure to Hazardous Chemicals in Laboratories."

\footnotetext{
${ }^{*} \mathrm{~K}=10$ implies no mixing; $\mathrm{K}=1$ implies perfect (ideal) mixing. Values between 3 and 5 are assumed to be conservative.
} 


\section{A.5 Hydrazine Detector Calibration Safety Video}

The ORNL Hydrazine Safety Course Video developed under this project has been provided to the Air Force on a compact disc (CD). For completeness of this document, the contents of the safety video are provided in Appendix B. 


\section{APPENDIX B \\ CONTENTS OF SLIDES IN ORNL SAFETY VIDEO}

\section{SECTION 1: INTRODUCTION AND COURSE OVERVIEW}

Hydrazine is a chemical that usually takes the form of a clear, colorless liquid. Safety training is needed for those who work with or around hydrazine because, in all its forms, it can be extremely hazardous to unprotected personnel. It can be absorbed into the body through the skin, by inhalation, and by ingestion. Regardless of how it enters the body, even trace amounts of hydrazine can have serious health and environmental impacts. Just a few drops of hydrazine on the skin can be fatal.

This training will describe and demonstrate procedures for working with hydrazine safely. It will cover using personal protective equipment correctly to avoid hydrazine exposure, procedures for handling hydrazine safely in the laboratory, exposure limits for hydrazine, and the steps to follow in calibrating hydrazine detectors.

If you follow these procedures without compromise, you can work with hydrazine without harm to yourself, other workers, or the environment. If you are careless or take short cuts, the results could be disastrous.

\section{SECTION 2: TOXICITY HAZARD}

\section{Slide 2A: Toxicity}

Toxicity can be defined as "the ability of a substance to cause injury once it reaches a susceptible site in or on the body."

Hydrazine in all its forms is toxic to humans and harmful to the environment.

\section{Slide 2B: Toxicity}

To evaluate the toxicity of hydrazine, three things must be considered: the route of entry into the body, the duration of exposure, and the concentration of the exposure

\section{Slide 2C: (Toxicity) - Routes of Entry into the Body}

\section{There are three main routes of entry into the body:}

- inhalation, which exposes the respiratory system, the lungs and mucous membranes to damage;

- ingestion, which exposes the tissues of the gastrointestinal tract and the mucous membranes; and

- absorption through the skin or eyes 


\section{Slide 2D: (Toxicity) - Duration of Exposure}

The duration of exposure to hydrazine is characterized as chronic, acute, or subchronic.

Chronic exposure is

- prolonged exposure, usually measured in weeks or more;

- repeated doses of the same chemical; and

- insidious, giving little or no clue of the damaging effects

Slide 2E: (Toxicity) - Duration of Exposure

Acute exposure is of short duration, usually measured in hours or less, and is a single dose. The effect of acute exposure is quick and noticeable.

Subchronic exposure is intermediate exposure, usually measured in days

Slide 2F: (Toxicity) - Concentration of Exposure

The exposure concentration refers to the dosage, or the amount taken into the body at a time.

Slide 2G: (Toxicity) - Exposure Limits

The U.S. Occupational Safety and Health Administration (OSHA) calls its limits permissible exposure limits, or PELs. The exposure limit used in OSHA regulations is the time-weighted average, which is 1 part per million, or1.3 milligrams of chemical per cubic meter of air.

PELs carry the force of law: they are regulations, not guidelines. They are binding unless a waiver is obtained. OSHA regulations are published annually in the Federal Register.

\section{Slide 2H: (Toxicity) - Exposure Limits}

The American Conference of Governmental Industrial Hygienists (ACGIH) has the most stringent exposure limit, which is expressed as a threshold limit value or TLV. The TLV for hydrazine is 0.01 parts per million, or 0.013 milligrams per cubic meter of air. The U.S. Air Force has adopted the ACGIH limits as its standard. 
Slide 2I: (Toxicity) - Exposure Limits

The National Institute for Occupational Safety and Health has established a limit of 50 parts per million of hydrazine as being immediately dangerous to life or health.

Slide 2J: (Toxicity) - General Symptoms of Hydrazine Exposure

\section{The general symptoms of exposure to hydrazine include:}

Throat and nose irritation

Eye irritation and burning

Breathing difficulties or bronchitis

Skin burns

Dizziness

Nausea and vomiting

Headache

Fever and chills

Tremors or convulsions, and

Abdominal pain

Slide 2K: (Toxicity) - General Conditions Arising from Hydrazine Exposure

These are the General conditions that can arise from hydrazine exposure:

Damage to corneas

Dermatitis

Pulmonary edema (fluid in the lungs)

Kidney damage

Liver damage

Central nervous system depression

Cyanosis, a bluish skin color due to lack of oxygen in the blood

Methemoglobinemia, or oxidized hemoglobin in the blood

Hemolysis, or destruction of red blood cells

Hematuria, or blood in the urine, and

Heinz bodies, which are spots in the red blood cells that may represent denatured proteins.

Reproductive anomalies have been observed in laboratory animals exposed to hydrazine

\section{Slide 2L: (Toxicity) - First Aid Procedures for Hydrazine Exposure}

There are several first aid procedures to deal with Hydrazine exposure. We'll begin with inhalation. Victims who have inhaled hydrazine vapor should be removed from the laboratory immediately and taken to fresh air. If the victim is not breathing, perform artificial respiration. Seek medical attention. 
In case of hydrazine ingestion, make the victim drink large amounts of water. Do not have the victim drink milk. Do not induce vomiting. Seek medical attention.

\section{Slide 2N: (Toxicity) - First Aid Procedures for Hydrazine Exposure}

In case of a hydrazine skin splash, remove the victim immediately from the contaminated area, remove the victim's clothing, and treat it as hazardous waste. Flush the affected areas with water for 15 to 20 minutes - just washing the area quickly is not sufficient. Seek medical attention for the victim.

\section{Slide 20: (Toxicity) - First Aid Procedures for Hydrazine Exposure}

In the case of hydrazine eye splash, move the victim from the contaminated area and immediately begin flushing the eyes with water, continuing for 15 to 20 minutes. As you flush the eyes, occasionally lift the upper and lower lids to ensure the eyes are washed completely. Seek medical attention.

In all cases of hazardous exposure to hydrazine by any route, report the exposure to a supervisor.

\section{Slide 2P: (Toxicity) - First Aid Procedures for Hydrazine Exposure}

Arch and Cedar/Vicksburg chemical companies provide emergency hotlines for cases of hydrazine poisoning.

\section{SECTION 3： PERSONAL PROTECTIVE EQUIPMENT (PPE)}

\section{Slide 3A: (PPE) - Harzard Assessment}

The handling of hydrazine permeation tubes during monitor calibration presents three potential hazards:

- a permeation tube that is leaking liquid or vapor,

- the puncture or slicing of a permeation tube, or

- bursting of a permeation tube caused by overheating 
Slide 3A2: (PPE) - Hydrazine Exposure Protection

Engineering controls are the primary means of reducing occupational exposures to hazards.

\section{Slide 3B: (PPE) - Hydrazine Exposure Protection}

A local exhaust (fume hood) system is used to keep the exposure of employees below the airborne exposure limits. Local exhaust ventilation is preferred because it controls emissions of the contaminant at the source and prevents them from dispersing into the work area. Consult the most recent edition of the ACGIH document Industrial Ventilation: A Manual of Recommended Practices for details.

\section{Slide 3C: (PPE) - Personal Protective Equipment}

Personal protective equipment supplements engineering controls in cases of

Emergencies

Failed engineering controls

Unproven or in-process controls or practices

Mobile or short-term work

\section{Slide 3D1-3D5: (PPE) - Hydrazine Exposure Protection}

The personal protective equipment necessary for handling hydrazine permeation tubes during monitor calibration consists of

- chemical goggles and a face shield,

- a lab coat and apron that are impervious to hydrazine spills, foe example, PVC or butyl and

- gloves and boots or shoe covers that are impervious to hydrazine spills, for example, PVC or butyl.

\section{Slide 3E: (PPE) - Hazard Assessment}

Before working in the laboratory with hydrazine, conduct a PPE hazard assessment to determine the type of level of protection required. Guidance can be found in the Non-mandatory Compliance Guidelines for Hazard Assessment and Personal Protective Equipment Selection, found in 29 Code of Federal Regulations 1910, Subpart 1, Appendix B.

\section{Slide 3F: PPE for Handling Hydrazine During Calibration of Detectors}


PPE to be used during calibration of hydrazine detectors in the laboratory includes

Skin protection

Wear hydrazine impervious protective clothing, including boots, gloves, a lab coat, an apron or coveralls, as appropriate, to prevent skin contact.

Eye protection

Use chemical safety goggles and a full face shield where splashing is possible. Maintain an eye washing fountain and quick-drench facilities within 10 seconds of the work area.

\section{Slide 3G: PPE Removal}

Getting out of PPE can be hazardous if it is not done properly, because you can expose yourself to chemical residues on your PPE.

Rinse off before removing contaminated clothing and equipment.

Don't touch contaminated surfaces while removing PPE. For example, remove aprons and shoe covers before taking off your gloves.

Dispose of all items of PPE properly.

Your employer should provide training on proper donning and removal of PPE.

\section{SECTION 4: HYDRAZINE DETECTION}

\section{Slide 4A: (Detection) - Vapor Exposure Limit}

The threshold limit value for hydrazine is $0.01 \mathrm{ppm}$.

The level considered by NIOSH to present an immediate danger to life and health is $50 \mathrm{ppm}$.

\section{Slide 4B: (Detection) - Uses of Monitors}

Monitors used for personnel protection are sensitive to 10 to $100 \mathrm{ppb}$.

Monitors for measuring residual contamination are sensitive to 100 to $1000 \mathrm{ppb}$.

Monitors used to detect leaks can detect levels of 0.1 to $10 \mathrm{ppm}$

\section{Slide 4C: (Detection) - Monitors are classified by the method of detection.}

- In colorometric monitors, a chemical reaction produces a color change.

- Spectroscopic monitors measure the absorbance or emittance of light. 
- Electrochemical monitors measure oxidation or reduction in a solution.

- Thermal monitors measure heat from a chemical reaction.

The Air Force uses colormetric, electrochemical and spectroscopic monitors.

\section{Slide 4D: (Detection) - Colorometric Monitors}

Dosimeter badges are colorometric monitors. These badges are usually passive. They indicate exposure by a color change over time. The dose can be estimated by comparing the badge with a color standard; an optical instrument can be used to read them.

\section{Slide 4E: (Detection) - Colorometric Monitors}

Paper tape monitors also are colormetric. Tape monitors sample actively using an air pump. A sample is pumped through a paper tape treated with an indicator, and the color change is read by optical reflectance or by transmittance. The tape advances to a fresh spot after the reading.

\section{Slide 4F: (Detection) - Colormetric Monitors}

Indicator tubes, another type of colormetric monitor, sample actively using an air pump. The length of the color change in the tube correlates with the chemical concentration.

\section{Slide 4G: (Detection) - Spectroscopic Monitors}

Spectroscopic monitoring is based on absorption of light. It measures light from the ultraviolet through the infrared spectra. A spectroscopic monitor requires a light source and a detector and requires long path lengths to probe enough molecules

\section{Slide 4H: (Detection) - Drawbacks and Limitations}

Potential drawbacks and limitations of hydrazine monitors include interference, response times, size and weight, complexity, and cost.

\section{Slide 4I: (Detection) - Common Interferants}

Substances that commonly interfere with readings from hydrazine monitors include ammonia, isopropyl alcohol, and hydrogen. 


\author{
Ideally, a monitor \\ Is sensitive to $10 \mathrm{ppb}$ \\ Is free from interference \\ Responds in 1 minute or less to 90\% of actual concentration \\ Can be reused after exposure to high concentrations \\ Is portable \\ Can be operated with one hand \\ Can be operated by personnel wearing splash gear or ILC protection \\ Is rugged - not affected by bumping or swinging \\ Has long calibration cycles \\ Is characterized for chemical and physical interference \\ Is capable of self-diagnostics (battery check, zero, etc.) \\ Can be operated with a charger when possible to minimize battery depletion \\ Has established, consistent performance specifications among different units
}

\title{
Slide 4L: (Detection) - Calibration of Monitors
}

Hydrazine monitors are calibrated by producing stable streams of hydrazine vapor of a known concentration - verified by analytical techniques - and exposing the monitors to the gas.

\section{Slide 4M: (Detection) - Producing Gas Streams}

A permeation system is used to produce a gas stream for calibrating hydrazine monitors. Small amounts of hydrazine are contained in Teflon tubes. These tubes introduce hydrazine vapor into a glass container, which has been flushed with nitrogen and is kept at a constant temperature. The hydrazine stream is combined with an air stream for dilution to the desired concentration.

\section{Slide 4N: (Detection) - Analysis of Gas Streams}

- Quantitative trapping of known gas volume

$>$ Sulfuric acid on firebrick

a Desorption into solution

- Analysis

$>$ Electrochemical measurement (coulometry)

- HPLC with electrochemical detection 


\section{SECTION 5: JOB DESIGN AND HANDLING (CODES)}

\section{Slide 5A: (Codes) - General}

Follow these general rules in working with hydrazine:

- Avoid skin or eye contact, breathing hydrazine vapor, or accidental ingestion through touching contaminated objects to the mouth

- Use hydrazine only in well-ventilated areas

- Do not store it at temperatures above 51 C $(124 \mathrm{~F})$

Slide 5B: (Codes) - Hydrazine Permeation Tubes Storage and Transfer Operations

- Store hydrazine permeation tubes in a cool, dry, well-ventilated location (for example, in a fume hood)

- Keep them under a nitrogen blanket

- Keep hydrazine containers closed except when they are in use

- Handle permeation tubes with forceps

- Avoid direct exposure of the tubes to sunlight or ultraviolet light

- Avoid allowing the hydrazine to contact metal oxides, high-surface-area organic materials, or

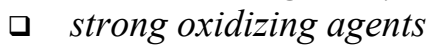

Slide 5C: (Codes) - Lab-Scale Handling

For detailed information on laboratory-scale handling of hydrazine, consult the

Chemical Hygiene Plan. You can link directly to it on the web.

The ORNL Chemical Hygiene Plan is at the url shown below.

http://sbms.ornl.gov/sbms/sbmsearch/subjarea/chemsafe/chp1.cfm

\section{SECTION 6: HYDRAZINE DETECTOR CALIBRATION OPERATOR SAFETY CHECKLIST}

Hydrazine used to calibrate monitors is sealed inside Teflon permeation tubes, which are heated to produce vapor streams. The safety checklist for the calibration process centers around a few simple rules for handling the tubes of hydrazine: never let hydrazine touch your skin, never let it near your mouth, never let it get into your eyes, and never breathe the vapor. Following the procedure outlined in the checklist will make a hazardous exposure to hydrazine unlikely.

Inspect and don PPE

Inspect and don personal hydrazine dosimeter

Check laboratory temperature, ventilation system, and hydrazine alarms 
Check operation of emergency eyewash and shower

Test hood ventilation system

Set up calibration equipment in fume hood and test

Test calibration system flow control and temperature control

Accidents that can occur during the calibration process include puncturing or slicing a tube or rupturing a tube by heating it beyond the bursting temperature.

Get hydrazine permeation tubes and install in gas standard generator

Connect device under test (DUT) to calibration system

Leak-test calibration setup, DUT, and connections

Do calibration

Remove and store hydrazine permeation tubes

Disconnect DUT from calibration system

Ensure no detectable hydrazine residuals

Inspect and doff PPE

Wash up BEFORE resuming any other activities

\section{SECTION 7: APPLICABLE CODES, STANDARDSAND REGULATIONS}

These codes, standards, and regulations contain more detailed information about safety standards related to the use of hydrazine. You can link directly to these documents on the Web:

OSHA Code of Federal Regulations: 29 CFR 1910 SUBPART Z

$\underline{\text { AFOSH } 48-8 \text { and AFOSH 48-22 }}$

$\underline{\text { ACGIH Hydrazine TLVs }}$

$\underline{\text { NIOSH Recommended Exposure Limit }}$ 


\section{INTERNAL DISTRIBUTION LIST}

1. R. P. Effler, Jr.

2. E. C. Fox

3. J. E. Hardy

4. R. A. Jenkins

5. K. Korsah

6. W. P. Murray

\author{
7. R. J. Quinn \\ 8. B. A. Tomkins \\ 9. Central Research Library \\ 10. ORNL Laboratory Records - RC \\ 11.-12. ORNL Laboratory Records - OSTI
}

\section{EXTERNAL DISTRIBUTION LIST}

13. Jim Baird, AFMETCAL, Det 1/ML, 813 Irving Wick Dr.W., Ste. 4M, Heath, OH 43056

14. David S. Madden, AFMETCAL, Det 1/ML, 813 Irving Wick Dr.W., Ste. 4M, Heath, OH 43056

15. Jim McKinley, Kin-Tek Laboratories, Inc., 504 Laurel, LaMarque, TX 77658

16. Robert C. Oesch, Zellweger Analytics, Inc., 405 Barclay Blvd, Lincolnshire, IL 60069

17. David Schick, AFMETCAL, Det 1/ML, 813 Irving Wick Dr.W., Ste. 4M, Heath, OH 43056

18. Joanne Schmitz, Zellweger Analytics, Inc., 405 Barclay Blvd., Lincolnshire, IL 60069

19. Rebecca Young, Kennedy Space Center, Technology Implementation Branch, Kennedy Space Center, FL 32899

20. Danet Vrazel, Kin-Tek Laboratories, Inc., 504 Laurel, LaMarque, TX 77658 